\title{
Numerical simulations of major ice streams in western Dronning Maud Land, Antarctica, under wet and dry basal conditions
}

\author{
Thomas KLEINER, Angelika HUMBERT \\ Alfred Wegener Institute for Polar and Marine Research, Bremerhaven, Germany \\ E-mail: thomas.kleiner@awi.de
}

\begin{abstract}
We study the presence and effect of subglacial water on the motion of inland ice in western Dronning Maud Land, Antarctica. A full-Stokes model including three routing schemes for a thin film of subglacial water and a modification of a Weertman-type sliding relation, to account for higher sliding velocities under wet basal conditions, were used to perform $200 \mathrm{ka}$ spin-up simulations on a $2.5 \mathrm{~km}$ grid. Subsequent 30 ka simulations with wet and dry basal conditions were analysed for the effects of sliding on the thermal regime and velocities. The occurrence of the major ice streams in this area is mainly controlled by the ice and bedrock geometry. Smaller glaciers only appear as pronounced individual glaciers when subglacial water is taken into account. The thermal regime is affected by creep instabilities produced by an ice rheology including a microscopic water content, leading to cyclic behaviour on millennial timescales of the ice flow and occurrence of temperate ice at the base.
\end{abstract}

KEYWORDS: basal melt, glacier hydrology, ice dynamics, ice-sheet modelling, ice streams

\section{INTRODUCTION}

Over the past decade it has become evident that subglacial water is widespread beneath the Antarctic ice sheet (Siegert, 2000; Siegert and others, 2005; Smith and others, 2009) and affects the ice dynamics on sub-annual timescales (Fricker and others, 2007; Stearns and others, 2008; Fricker and Scambos, 2009). These observations dealt with water on horizontal scales of kilometres and vertical scales of tens of centimetres to metres (i.e. lakes and hydraulic connections between lakes). Here we focus on the effect of a thin water layer on the dynamics of ice sheets.

Underneath a thick ice sheet the basal temperature locally reaches the pressure-melting point and melt rates of the order of millimetres per year may generate a subglacial water layer. This basal water lubricates the base. A thought-experiment helps us to understand the consequences. Let us begin with an ice sheet frozen to the base. Large ice deformation at the base produces heat (strain heating) when ice is frozen to the base. The heating may lead to a temperate ice layer at the base. In this temperate layer the deformation is enhanced due to the reduced viscosity caused by microscopic water inclusions; temperate ice is soft. Ice with a temperate base is lubricated by subglacial meltwater, which enhances the sliding velocity. Basal sliding additionally leads to frictional heating at the base. A further consequence of the initiation of sliding is that the reduction of shear decreases the heat source of internal strain heating and, over time, the basal layer cools. When heat transport by geothermal and frictional heat into the ice does not counterbalance this cooling, the ice again becomes frozen to the bedrock.

The effect of subglacial water is thus twofold: it affects the sliding and the thermal regime, and in both these ways affects the ice flow. Subglacial water is therefore a crucial component in the dynamic evolution of ice sheets and needs to be incorporated into ice-sheet models. Here we investigate the effect of water at the ice base on sliding, deformation and the thermal regime.

Modelling the ice flow at a horizontal scale of the order of the ice thickness, and thus precise predictions of mass balance, requires the solution of the momentum-balance equations for all stresses (full-Stokes), since high gradients in geometry and the change of basal sliding properties arise on short length scales (Pattyn and others, 2008). Studying the effect of subglacial water on the dynamics of ice streams requires coupling the hydrological system with the sliding properties, hence the velocity at the base of the ice sheet depends on water flux or water pressure. This simplest approach to subglacial water is incorporated into the fullStokes model TIM-FD³ (Kleiner, 2010).

For the application we have chosen an area in which a variety of ice-sheet elements occur: large and medium ice streams, small glaciers, a mountain range with rock outcrops and stagnant flow. A suitable area with these characteristics, which is also reasonably surveyed, is located in western Dronning Maud Land, Antarctica, where two major ice streams drain into the adjacent Riiser-Larsen and Brunt Ice Shelves. An additional reason for choosing this area is that a previous modelling study (Humbert and others, 2009) optimized the settings for the ice shelves, assuring us that we have a good represention of the buttressing effect of the ice shelves.

\section{MODEL DESCRIPTION}

The new three-dimensional (3-D) numerical ice-flow model, TIM-FD ${ }^{3}$, estimates the ice thickness and the 3-D flow regime (velocity, strain rate and stress fields), as well as the temperature distribution in response to environmental/ boundary conditions. The model is implemented as a 'multilayer model' (cf. Hindmarsh, 2004), but with all stresses included in the momentum balance. Due to the reduced number of variables that need to be solved by linear sparse matrix solvers, the model is relatively fast and allows long integration times.

In the following discussions, $x$ and $y$ are the horizontal dimensions, $z$ is the vertical dimension (positive upwards) and $t$ is the time. The elevations of the upper and lower ice surface, $z_{\mathrm{s}}=h(x, y, t)$ and $z_{\mathrm{b}}=h(x, y, t)-H(x, y, t)$, respectively, vary spatially as well as temporally, where $H$ is the ice thickness. For this reason we use terrain-following 
coordinates, $(\xi, \eta, \zeta, \tau)$, in which the transformation is implemented by

$$
\xi=x, \quad \eta=y \quad \zeta=\frac{z-z_{\mathrm{b}}}{z_{\mathrm{s}}-z_{\mathrm{b}}} \quad \text { and } \quad \tau=t .
$$

The new vertical coordinate, $\zeta$, maps the local ice thickness onto unity such that $\zeta=1$ at the surface and $\zeta=0$ at the base. Although we change the coordinates, we still use vectors and tensors in terms of their components relative to the Cartesian base vectors. Partial derivatives according to the Cartesian coordinates must therefore be transformed to the new coordinates by applying the chain-rule

$$
\frac{\partial}{\partial x}=\frac{\partial \xi}{\partial x} \frac{\partial}{\partial \xi}+\frac{\partial \eta}{\partial x} \frac{\partial}{\partial \eta}+\frac{\partial \zeta}{\partial x} \frac{\partial}{\partial \zeta}+\frac{\partial \tau}{\partial x} \frac{\partial}{\partial \tau}
$$

and similarly for $\partial / \partial y, \partial / \partial z$ and $\partial / \partial t$ (cf. Greve and Blatter, 2009, p.91-92). Many of the coordinate derivatives, $\partial \xi_{i} / \partial x_{j}$, vanish and

$$
\begin{array}{rlrl}
\frac{\partial}{\partial x} & =\frac{\partial}{\partial \xi}+\frac{c_{x}}{H} \frac{\partial}{\partial \zeta}, & c_{x}=(1-\zeta) \frac{\partial H}{\partial \xi}-\frac{\partial H}{\partial \xi} \\
\frac{\partial}{\partial y} & =\frac{\partial}{\partial \eta}+\frac{c_{y}}{H} \frac{\partial}{\partial \zeta^{\prime}}, & c_{y}=(1-\zeta) \frac{\partial H}{\partial \eta}-\frac{\partial H}{\partial \eta} \\
\frac{\partial}{\partial z} & =\frac{1}{H} \frac{\partial}{\partial \zeta} \\
\frac{\partial}{\partial t} & =\frac{\partial}{\partial \tau}+\frac{c_{t}}{H} \frac{\partial}{\partial \zeta^{\prime}}, & c_{t}=(1-\zeta) \frac{\partial H}{\partial \tau}-\frac{\partial H}{\partial \tau}
\end{array}
$$

where all derivatives are affected by the vertical scaling. Note that, although $\xi=x, \eta=y$ and $\tau=t$, the entire spatiotemporal coordinate transformation needs to be considered.

\section{Stokes flow}

The flow of ice is modelled using the full-Stokes set of equations containing the conservation of mass and momentum. For an incompressible fluid they read in coordinate-free form as

$$
\operatorname{div} \boldsymbol{u}=0
$$

and

$$
\operatorname{div} \boldsymbol{S}+\rho \boldsymbol{g}=0,
$$

where $\operatorname{div} \boldsymbol{u}$ is the divergence of the velocity vector, $\boldsymbol{u}$, with components $u_{i} \in\{u, v, w\}, \boldsymbol{S}$ is the Cauchy stress tensor, with components $\sigma_{i j}, i, j \in\{x, y, z\}$, and $\rho \mathbf{g}$ is the volume force due to the density, $\rho$, and acceleration due to gravity, g. It is assumed that (1) body forces other than those arising from gravity can be neglected, due to the very slow flow and high viscosity, (2) density variations can be neglected, except in the gravitational term, $\rho \mathbf{g}$, and (3) inertial (convective) terms can be ignored compared with gravity. The Cauchy stress tensor is given by

$$
\boldsymbol{S}=\boldsymbol{T}-p \boldsymbol{I} \text { and } p=-1 / 3 \operatorname{tr}(\boldsymbol{S}),
$$

where $p \boldsymbol{I}$ and $\boldsymbol{T}$ are the isotropic and deviatoric parts of $\boldsymbol{S}$, respectively, $\boldsymbol{I}$ is the identity tensor and $\operatorname{tr}(\cdot)$ is the trace operator. The isotropic pressure, $p$, is in general not equal to the hydrostatic pressure as used in the shallow-ice approximation (SIA). Following Whillans (1987) and Van der Veen and Whillans (1989a), the full-stress components from Eqn (9) can alternatively be partitioned into a resistive, $\boldsymbol{R}$, and a cryostatic, $L$, component, so that

$$
\boldsymbol{S}=\boldsymbol{R}-L \boldsymbol{I} \quad \text { and } \quad L=\bar{\rho} g H(1-\zeta),
$$

where $\boldsymbol{R}$ is a tensor with components $R_{i j}, i, j \in\{x, y, z\}$ and

$$
\bar{\rho}(\zeta)=\frac{1}{1-\zeta} \int_{\zeta}^{1} \rho\left(\zeta^{\prime}\right) \mathrm{d} \zeta^{\prime}
$$

is the mean density of the overlying ice mass in the selected ice column. Both representations (Eqns (9) and (10)) of the Cauchy stress tensor are used in the text below. The deformation of polycrystalline ice is modelled using the commonly used Nye generalization (Nye, 1957) of the Glen-Steinemann power-law rheology (Glen, 1955; Steinemann, 1954, 1958) given by

$$
\boldsymbol{T}=2 \mu \boldsymbol{D} \quad \text { and } \quad \mu=\frac{1}{2}(E A)^{-\frac{1}{n}} \dot{\varepsilon}^{\frac{1-n}{n}},
$$

where $\boldsymbol{D}$ is the strain-rate tensor with components $\dot{\varepsilon}_{i j}$, $i, j \in\{x, y, z\}, \mu$ is the effective viscosity, $n=3$ is the power-law exponent, $A$ is the flow-rate factor, $\dot{\varepsilon}_{\mathrm{e}}$ is the effective strain rate (second invariant of $\boldsymbol{D}$ ) and $E$ is the flowenhancement factor that parameterizes other physical contributions (e.g. impurities or damage). To avoid an infinite viscosity for vanishing effective strain rates we add a small $\dot{\varepsilon}_{0}=10^{-30} \mathrm{~s}^{-1}$ to $\dot{\varepsilon}_{\mathrm{e}}$ in Eqn (12). The flow-rate factor is parameterized as an Arrhenius relationship (Paterson and Budd, 1982; Paterson, 1994):

$$
A\left(T^{*}\right)=A_{0} \mathrm{e}^{-Q / R T^{*}} \quad \text { and } \quad T^{*}=T+\gamma p,
$$

where $A_{0}$ is a temperature-independent material constant, $Q$ is the activation energy for creep, $R$ is the universal gas constant, $T$ is the temperature, $T^{*}$ is the homologous temperature (absolute temperature corrected for the dependence of the melting point on pressure) and $\gamma$ is the ClausiusClapeyron constant. The values for $A_{0}, Q$ and $R$ are taken from Paterson (1994). If the ice reaches the pressure-melting point $\left(T_{\mathrm{pmp}}\right)$, the rate factor in Eqn (13) is replaced by a rate factor depending also on the microscopic water content, $W$, following Duval (1977) and Lliboutry and Duval (1985):

$$
A(W)=A\left(T^{*}=T_{\mathrm{pmp}}\right)(1+181.25 W)
$$

as commonly used in numerical models (e.g. Aschwanden and others, 2012; Sato and Greve, 2012). We do not solve for the water content explicitly, but assume a water content of $W=0.01(1 \%)$ for each gridpoint that is at the pressuremelting point. The chosen value is the upper limit of the validity range of Eqn (14) (Lliboutry and Duval, 1985). In our simulations we use $W=0$ and $W=0.01$, taken as the upper and lower limits of the water content. We further use the terms cold and temperate ice rheology in the following text and refer to Eqns (13) and (14) respectively.

By integrating the vertical component of Eqn (8) from the bottom to the ice upper surface and assuming a traction-free ice surface, the pressure at a certain position inside the ice can be found as (Van der Veen and Whillans, 1989b)

$$
-p=\tau_{x x}+\tau_{y y}+R_{z z}-g H \int_{\zeta}^{1} \rho\left(\zeta^{\prime}\right) \mathrm{d} \zeta^{\prime},
$$

with vertical resistive stress,

$$
R_{z z}=\frac{\partial}{\partial \xi}\left(H \int_{\zeta}^{1} \tau_{x z} \mathrm{~d} \zeta^{\prime}\right)+\frac{\partial}{\partial \eta}\left(H \int_{\zeta}^{1} \tau_{y z} \mathrm{~d} \zeta^{\prime}\right)
$$

accounting for bridging effects. The total isometric pressure, $p$, therefore consists of a dynamic part and a cryostatic part (last term in Eqn (15)). Based on the definition of the strain- 
rate tensor,

$$
\boldsymbol{D}=\frac{1}{2}\left[\operatorname{grad} \boldsymbol{u}+(\operatorname{grad} \boldsymbol{u})^{\top}\right],
$$

each component of the tensor can be derived using general tensor analysis methods (e.g. Aris, 1989) as

$$
\dot{\varepsilon}_{i j}=\frac{1}{2}\left(\sum_{k=1}^{3} \frac{\partial \xi_{k}}{\partial x_{j}} \frac{\partial u_{i}}{\partial \xi_{k}}+\frac{\partial \xi_{k}}{\partial x_{i}} \frac{\partial u_{j}}{\partial \xi_{k}}\right),
$$

with $\xi_{i} \in\{\xi, \eta, \zeta\}, x_{i} \in\{x, y, z\}$ and $u_{i} \in\{u, v, w\}$. Together with the divergence of the stress tensor

$$
\operatorname{div} \boldsymbol{S}=\sum_{i=1}^{3}\left[\frac{1}{H} \sum_{k=1}^{3} \frac{\partial}{\partial \xi_{k}}\left(H \sum_{j=1}^{3} \frac{\partial \xi_{k}}{\partial x_{j}} \sigma_{i j}\right)\right] \mathbf{e}_{i,}
$$

where $\boldsymbol{e}_{i} \in\left\{\boldsymbol{e}_{x}, \boldsymbol{e}_{y}, \mathbf{e}_{z}\right\}$ is the Cartesian basis, the horizontal components of the momentum balance (Eqn (8)) can be written in terms of the velocity field as

$$
\begin{aligned}
& 4 \frac{\partial}{\partial \xi}\left(H \mu \frac{\partial u}{\partial \xi}\right)+4 \frac{\partial}{\partial \zeta}\left(c_{x} \mu \frac{\partial u}{\partial \xi}\right)+\frac{\partial}{\partial \eta}\left(H \mu \frac{\partial u}{\partial \eta}\right) \\
+ & \frac{\partial}{\partial \zeta}\left(c_{y} \mu \frac{\partial u}{\partial \eta}\right)+4 \frac{\partial}{\partial \xi}\left(c_{x} \mu \frac{\partial u}{\partial \zeta}\right)+\frac{\partial}{\partial \eta}\left(c_{y} \mu \frac{\partial u}{\partial \zeta}\right) \\
+ & \frac{\partial}{\partial \zeta}\left(\frac{4 c_{x}^{2}+c_{y}^{2}+1}{H} \mu \frac{\partial u}{\partial \zeta}\right)= \\
& \frac{\partial}{\partial \xi}(H L)+\frac{\partial}{\partial \zeta}\left(c_{x} L\right)-\frac{\partial}{\partial \xi}\left(H R_{z z}\right)-\frac{\partial}{\partial \zeta}\left(c_{x} R_{z z}\right) \\
- & \frac{\partial}{\partial \zeta}\left(c_{y} \mu \frac{\partial v}{\partial \xi}\right)-\frac{\partial}{\partial \eta}\left(H \mu \frac{\partial v}{\partial \xi}\right)-2 \frac{\partial}{\partial \zeta}\left(c_{y} \mu \frac{\partial v}{\partial \eta}\right) \\
- & \frac{\partial}{\partial \xi}\left(H \mu \frac{\partial v}{\partial \eta}\right)-\frac{\partial}{\partial \eta}\left(c_{x} \mu \frac{\partial v}{\partial \zeta}\right)-2 \frac{\partial}{\partial \xi}\left(c_{y} \mu \frac{\partial v}{\partial \zeta}\right) \\
- & 3 \frac{\partial}{\partial \zeta}\left(\frac{c_{x} c_{y}}{H} \mu \frac{\partial v}{\partial \zeta}\right)-\frac{\partial}{\partial \zeta}\left(\mu \frac{\partial w}{\partial \xi}\right)-\frac{\partial}{\partial \zeta}\left(\frac{c_{x}}{H} \mu \frac{\partial w}{\partial \zeta}\right),
\end{aligned}
$$

and similarly for the velocity component, $v$ :

$$
\begin{aligned}
& \frac{\partial}{\partial \xi}\left(H \mu \frac{\partial v}{\partial \xi}\right)+\frac{\partial}{\partial \zeta}\left(c_{x} \mu \frac{\partial v}{\partial \xi}\right)+4 \frac{\partial}{\partial \eta}\left(H \mu \frac{\partial v}{\partial \eta}\right) \\
+ & \frac{\partial}{\partial \zeta}\left(c_{y} \mu \frac{\partial v}{\partial \eta}\right)+4 \frac{\partial}{\partial \eta}\left(c_{y} \mu \frac{\partial v}{\partial \zeta}\right)+\frac{\partial}{\partial \xi}\left(c_{x} \mu \frac{\partial v}{\partial \zeta}\right) \\
+ & \frac{\partial}{\partial \zeta}\left(\frac{c_{x}^{2}+4 c_{y}^{2}+1}{H} \mu \frac{\partial v}{\partial \zeta}\right)= \\
& \frac{\partial}{\partial \eta}(H L)+\frac{\partial}{\partial \zeta}\left(c_{y} L\right)-\frac{\partial}{\partial \eta}\left(H R_{z z}\right)-\frac{\partial}{\partial \zeta}\left(c_{y} R_{z z}\right) \\
-2 & \frac{\partial}{\partial \zeta}\left(c_{y} \mu \frac{\partial u}{\partial \xi}\right)-2 \frac{\partial}{\partial \eta}\left(H \mu \frac{\partial u}{\partial \xi}\right)-\frac{\partial}{\partial \zeta}\left(c_{x} \mu \frac{\partial u}{\partial \eta}\right) \\
- & \frac{\partial}{\partial \xi}\left(H \mu \frac{\partial u}{\partial \eta}\right)-2 \frac{\partial}{\partial \eta}\left(c_{x} \mu \frac{\partial u}{\partial \zeta}\right)-\frac{\partial}{\partial \xi}\left(c_{y} \mu \frac{\partial u}{\partial \zeta}\right) \\
-3 & \frac{\partial}{\partial \zeta}\left(\frac{c_{x} c_{y}}{H} \mu \frac{\partial u}{\partial \zeta}\right)-\frac{\partial}{\partial \zeta}\left(\mu \frac{\partial w}{\partial \eta}\right)-\frac{\partial}{\partial \zeta}\left(\frac{c_{y}}{H} \mu \frac{\partial w}{\partial \zeta}\right) .
\end{aligned}
$$

An expression for the vertical velocity, $w$, is obtained through the incompressibility condition (Eqn (7)), as

$$
\frac{1}{H} \frac{\partial w}{\partial \zeta}=-\left(\frac{\partial u}{\partial \xi}+\frac{c_{x}}{H} \frac{\partial u}{\partial \zeta}+\frac{\partial v}{\partial \eta}+\frac{c_{y}}{H} \frac{\partial v}{\partial \zeta}\right) .
$$

We also reformulate Eqn (16) as

$$
\frac{1}{H} \frac{\partial R_{z z}}{\partial \zeta}=\left(\frac{\partial \tau_{x z}}{\partial \xi}+\frac{C_{x}}{H} \frac{\partial \tau_{x z}}{\partial \zeta}+\frac{\partial \tau_{y z}}{\partial \eta}+\frac{c_{y}}{H} \frac{\partial \tau_{y z}}{\partial \zeta}\right),
$$

Table 1. Used constants and model parameters

\begin{tabular}{lc}
\hline Quantity & Value \\
\hline Seconds per year & $31556926 \mathrm{~s} \mathrm{a}^{-1}$ \\
Gravitational acceleration, $g$ & $9.81 \mathrm{~m} \mathrm{~s}^{-2}$ \\
Density of ice, $\rho$ & $910 \mathrm{~kg} \mathrm{~m}^{-3}$ \\
Density of water, $\rho_{\mathrm{W}}$ & $1000 \mathrm{~kg} \mathrm{~m}^{-3}$ \\
Density of sea water, $\rho_{\mathrm{SW}}$ & $1028 \mathrm{~kg} \mathrm{~m}^{-3}$ \\
Specific heat capacity, $C_{p}(T)$ & $(146.3+7.253 \mathrm{~T}) \mathrm{J} \mathrm{kg}^{-1} \mathrm{~K}^{-1}$ \\
Thermal conductivity, $\kappa(T)$ & $9.821 \mathrm{e}^{-0.0057 T} \mathrm{~W} \mathrm{~m}^{-1} \mathrm{~K}^{-1}$ \\
Latent heat of fusion, $L$ & $3.35 \times 10^{5} \mathrm{~J} \mathrm{~kg}^{-1}$ \\
Clausius-Clapeyron constant, $\gamma$ & $9.8 \times 10^{-8} \mathrm{KPa}^{-1}$ \\
Melting point at atmospheric pressure, $T_{0}$ & $273.15 \mathrm{~K}$ \\
Sliding parameter, $C_{\mathrm{b}}^{0}$ & $10^{3}(\rho g)^{-1} \mathrm{a}^{-1}$ \\
Sliding exponent, $(p, q)$ & $(3,2)$ \\
Sub-melt sliding parameter, $\nu$ & 4 \\
Viscosity of water, $\mu_{\mathrm{w}}$ & $1.8 \times 10^{-3} \mathrm{~Pa} \mathrm{~s}^{\circ}$ \\
Ocean surface temperature, $T_{\mathrm{ocn}}$ & $-2^{\circ} \mathrm{C}$ \\
Convergence parameter, $\epsilon_{\mathrm{res}}$ & $1 \times 10^{-6}$ \\
Convergence parameter, $\epsilon_{\mathrm{rel}}$ & $5 T \times 10^{-4}$ \\
Convergence parameter, $\epsilon_{\mathrm{abs}}$ & $1 \times 10^{-4} \mathrm{~m} \mathrm{a}^{-1}$ \\
& \\
& \\
&
\end{tabular}

where the deviatoric stress components can be found from Eqns (12) and (18).

\section{Heat transport}

The general heat transfer by advection and diffusion with internal heat sources can be written as

$$
\rho c_{p}\left(\frac{\partial T}{\partial t}+\boldsymbol{u} \cdot \operatorname{grad} T\right)=\operatorname{div}(\kappa \operatorname{grad} T)+\psi,
$$

where $c_{p}(T)$ and $\kappa(T)$ are the specific heat capacity and thermal conductivity of ice. Strain heating,

$$
\psi=\operatorname{tr}(\boldsymbol{T} \cdot \boldsymbol{D})=4 \mu \dot{\varepsilon}_{\mathrm{e}^{\prime}}^{2}
$$

due to the deformation of ice, is the only heat source considered in the interior of the ice.

We further follow the analysis of Paterson (1994) and neglect horizontal diffusion of heat, which is small compared with horizontal advection, and consider spatial variations in the thermal conductivity only vertically. Using the transformation rules for the partial derivatives (Eqns (36)), Eqn (24) can be written in coordinate-dependent form as

$$
\frac{\partial T}{\partial \tau}=-u \frac{\partial T}{\partial \xi}-v \frac{\partial T}{\partial \eta}-w^{*} \frac{\partial T}{\partial \zeta}+K \frac{\partial^{2} T}{\partial \zeta^{2}}+S,
$$

with

$$
\begin{aligned}
w^{*} & =\frac{1}{H}\left(w-\frac{1}{\rho c_{p} H} \frac{\partial \kappa}{\partial \zeta}+u c_{x}+v c_{y}+c_{t}\right), \\
K & =\frac{\kappa}{\rho c_{p} H^{2}}
\end{aligned}
$$

and

$$
S=\frac{\psi}{\rho c_{p}},
$$

where $w^{*}$ is the effective vertical velocity, $K$ is the vertically scaled diffusivity and $S$ is the heat source term. The implicit dependency of $\kappa$ on temperature (Table 1) makes Eqn (26) nonlinear and reinforces downward advection due to the additional velocity term, $1 /\left(\rho c_{p} H^{2}\right) \partial \kappa / \partial \zeta$. The remaining part, $\left(u c_{x}+v c_{y}+c_{t}\right) / H$, accounts for the spatial-temporal coordinate transformation as a vertical grid velocity. The ice temperature is always kept below or equal to the 
pressure-melting point. Thus all heat that exceeds this limit is used for melting ice.

If the base is at the pressure-melting point and a basal layer of temperate ice exists, then the temperature gradient in the layer prevents the inflow of frictional and geothermal heat, so all that heat melts ice at the base as

$$
M_{\mathrm{b}}=\frac{1}{\rho L}\left(\left.\frac{\kappa}{H} \frac{\partial T^{*}}{\partial \zeta}\right|_{\mathrm{b}}+q_{\text {geo }}+q_{\text {frict }}\right),
$$

where $L$ is the specific latent heat of fusion, $q_{\text {geo }}$ is the geothermal heat flux into the ice and $q_{\text {frict }}=\boldsymbol{u}_{\mathrm{b}} \cdot \boldsymbol{\tau}_{\mathrm{b}}$ is the frictional heat.

It is assumed that meltwater generated within a temperate basal ice layer drains away to the base immediately and contributes to the total basal mass balance according to

$$
M_{\mathrm{i}}=\frac{H}{\rho L} \int_{0}^{\zeta \mathrm{CTS}} \psi(\zeta) \mathrm{d} \zeta,
$$

where $\zeta_{\text {CTs }}$ is the cold transition surface (the interface between temperate and cold ice). Thus, $a_{b}=-\left(M_{b}+M_{i}\right)$ is the total basal mass balance (mice eq. $\mathrm{a}^{-1}$, positive for freezing) at a given grounded ice position.

\section{Evolution of the ice thickness}

The evolution of the ice thickness is a direct consequence of the mass conservation expressed by the incompressibility, Eqn (7). The local horizontal ice flux that determines the evolution of the local ice thickness is obtained by integrating Eqn (7) from the bottom, $z_{b}$, to the ice surface, $z_{s}$,

$$
\frac{\partial H}{\partial t}=-\frac{\partial}{\partial x}\left(H \int_{0}^{1} u(\zeta) \mathrm{d} \zeta\right)-\frac{\partial}{\partial y}\left(H \int_{0}^{1} v(\zeta) \mathrm{d} \zeta\right)+a_{\mathrm{s}}+a_{\mathrm{b}}
$$

where $a_{\mathrm{s}}=a_{\mathrm{s}}(x, y, t)$ and $a_{\mathrm{b}}=a_{\mathrm{b}}(x, y, t)$ are the surface and basal mass balances, respectively. They are given by the kinematic boundary conditions at the ice surface and base,

$$
\frac{\partial z_{\mathrm{s}}}{\partial t}+u \frac{\partial z_{\mathrm{s}}}{\partial x}+v \frac{\partial z_{\mathrm{s}}}{\partial y}-w=a_{\mathrm{s}}
$$

and

$$
\frac{\partial z_{\mathrm{b}}}{\partial t}+u \frac{\partial z_{\mathrm{b}}}{\partial x}+v \frac{\partial z_{\mathrm{b}}}{\partial y}-w=-a_{\mathrm{b}}
$$

prescribing the motion of these free surfaces relative to the motion of ice, where $u, v$ and $w$ are taken at the surface and at the base, respectively. The signs of $a_{\mathrm{s}}$ and $a_{\mathrm{b}}$ are chosen to be negative for mass loss due to, for example, surface ablation or basal melting. At all lateral boundaries the ice thickness is prescribed. The calving front position is assumed to be constant in time, so no kinematic boundary condition needs to be given at the calving front.

\section{Boundary conditions}

\section{Basal interface}

At the ice base, $z_{\mathrm{b}}=h(x, y, t)-H(x, y, t)$, or $\zeta_{\mathrm{b}}=0$, shear stresses act in the tangential plane, and the normal stress must be compensated from the bedrock or water at the base

$$
\begin{gathered}
\boldsymbol{t} \cdot(\boldsymbol{S} \cdot \boldsymbol{n})=-\beta^{2} \boldsymbol{t} \cdot \boldsymbol{u} \\
\boldsymbol{b} \cdot(\boldsymbol{S} \cdot \boldsymbol{n})=-\beta^{2} \boldsymbol{b} \cdot \boldsymbol{u}
\end{gathered}
$$

and

$$
\boldsymbol{n} \cdot(\boldsymbol{S} \cdot \boldsymbol{n})=-\bar{\rho} g H \boldsymbol{n},
$$

where $\bar{\rho}$ is the mean density of the ice column and $\boldsymbol{t}$ and $\boldsymbol{b}$ are the tangent and bi-normal unit vectors at the base. Although $\boldsymbol{t}$ and $\boldsymbol{b}$ could be arbitrary orthogonal vectors in the tangential plane at the lower surface, they are chosen to be aligned in the $x-z$ plane and $y-z$ plane, pointing into positive $x$ - and $y$-directions, respectively. With this alignment the unit normal vector at the base is $\boldsymbol{n}=\boldsymbol{b} \times \boldsymbol{t}$ and points outside the ice. The basal drag parameter, $\beta^{2}(x, y, t)$ (e.g. MacAyeal and others, 1995), is an always-positive scalar field that in general varies in space and time and needs to be prescribed or parameterized by a sliding relation (see Eqn (56), below). The signs in Eqns (35) and (36) account for the orientation of $\boldsymbol{t}$ and $\boldsymbol{b}$, so basal stresses oppose ice motion.

To obtain boundary conditions related to the horizontal velocity field we first use Eqn (37) to compute the pressure inside the ice,

$$
\begin{aligned}
\left.p\right|_{\mathrm{b}}= & -2 \mu \frac{\partial u}{\partial \xi}-\frac{c_{x} \mu}{H} \frac{\partial u}{\partial \zeta}-2 \mu \frac{\partial v}{\partial \eta}-\frac{c_{y} \mu}{H} \frac{\partial v}{\partial \zeta} \\
& +c_{x} \mu \frac{\partial w}{\partial \xi}+c_{y} \mu \frac{\partial w}{\partial \eta}+\frac{\left(c_{x}^{2}+c_{y}^{2}\right) \mu}{H} \frac{\partial w}{\partial \zeta}+\bar{\rho} g H
\end{aligned}
$$

and then eliminate the pressure term in Eqns (35) and (36), thus:

$$
\begin{aligned}
4 c_{x} \frac{\partial u}{\partial \xi} & +c_{y} \frac{\partial u}{\partial \eta}+\frac{3 c_{x}^{2}+c_{y}^{2}+1}{H} \frac{\partial u}{\partial \zeta}+\frac{\beta^{2} u}{\mu}= \\
& -c_{y} \frac{\partial v}{\partial \xi}-2 c_{x} \frac{\partial v}{\partial \eta}-\frac{2 c_{x} c_{y}}{H} \frac{\partial v}{\partial \zeta} \\
& +\left(c_{x}^{2}-1\right) \frac{\partial w}{\partial \xi}+c_{x} c_{y} \frac{\partial w}{\partial \eta}+\frac{c_{x} c_{y}^{2}+c_{x}\left(c_{x}^{2}-1\right)}{H} \frac{\partial w}{\partial \zeta}
\end{aligned}
$$

$$
\begin{aligned}
& c_{x} \frac{\partial v}{\partial \xi}+4 c_{y} \frac{\partial v}{\partial \eta}+\frac{c_{x}^{2}+3 c_{y}^{2}+1}{H} \frac{\partial v}{\partial \zeta}+\frac{\beta^{2} v}{\mu}= \\
& \quad-2 c_{y} \frac{\partial u}{\partial \xi}-c_{x} \frac{\partial u}{\partial \eta}+\frac{2 c_{x} c_{y}}{H} \frac{\partial u}{\partial \zeta} \\
& \quad+c_{x} c_{y} \frac{\partial w}{\partial \xi}+\left(c_{y}^{2}-1\right) \frac{\partial w}{\partial \eta}+\frac{c_{x}^{2} c_{y}+c_{y}\left(c_{y}^{2}-1\right)}{H} \frac{\partial w}{\partial \zeta}
\end{aligned}
$$

For the floating part of the base $\beta^{2}=0$ (no basal traction). The basal vertical velocity component can be derived from the kinematic boundary condition (Eqn (34)) at the lower surface:

$$
w_{\mathrm{b}}=\frac{\partial z_{\mathrm{b}}}{\partial t}+u \frac{\partial z_{\mathrm{b}}}{\partial x}+v \frac{\partial z_{\mathrm{b}}}{\partial y}+a_{\mathrm{b}} .
$$

In this study we do not evolve the ice geometry, so $\partial z_{\mathrm{b}} / \partial t=0$ for all time-steps.

The temperature boundary condition at the grounded ice base depends on whether the ice is at the pressure-melting point or not. If the grounded ice base is below the pressuremelting point the following Neumann boundary condition applies:

$$
\left.\frac{\partial T}{\partial \zeta}\right|_{\mathrm{b}}=H\left(q_{\text {geo }}+q_{\text {frict }}\right) / \kappa, \quad \text { if } \quad T<T_{\text {pmp }} .
$$

The frictional heating, $q_{\text {frict }}$, needs to be considered in this case only if basal sliding below the pressure-melting point is allowed. A second condition applies to basal ice at the pressure-melting point when the geothermal heat flux plus the heat flux generated by basal friction heating (sliding) is 
larger than the heat flux from the bed into the ice (Payne and Dongelmans, 1997),

$$
\left.T\right|_{\mathrm{b}}=T_{\text {pmp }} \quad \text { if }\left.\quad \frac{\partial T^{*}}{\partial \zeta}\right|_{\mathrm{b}}<H\left(q_{\text {geo }}+q_{\text {frict }}\right) / \kappa,
$$

and reads as the Dirichlet boundary condition. If the condition in Eqn (43) cannot be fulfilled, again Eqn (42) applies as the Neumann condition for the temperate ice base. The 'if' condition in Eqn (43) allows the temperature at the base to be less than the pressure-melting point during thermal evolution, even if the pressure-melting point was reached once. As a common approximation in ice-sheet and glacier models (Payne and Dongelmans, 1997; Pattyn, 2003, 2010), the geothermal heat flux is assumed to be temporally constant and independent of heat transport in the bedrock, so changes in heat storage in the underlying bedrock cannot affect the basal heat budget in the ice model. We have further assumed that $\kappa\left(\operatorname{grad} T \cdot \boldsymbol{n}_{\mathrm{b}}\right) \approx(\kappa / H) \frac{\partial T}{\partial \zeta}$. At the ice/ocean interface the ocean surface temperatures, $\left.T\right|_{\mathrm{b}}=T_{\mathrm{ocn}}(x, y, t)$, are prescribed as the Dirichlet boundary condition.

\section{Upper interface}

At the upper surface, $z_{\mathrm{s}}=h(x, y, t)$ or $\zeta_{\mathrm{s}}=1$, the tangential (wind) and normal (pressure) atmospheric stresses are assumed to be small compared with typical stresses in the ice and can therefore be neglected:

$$
\begin{aligned}
\boldsymbol{t} \cdot(\boldsymbol{S} \cdot \boldsymbol{n}) & =0, \\
\boldsymbol{b} \cdot(\boldsymbol{S} \cdot \boldsymbol{n}) & =0
\end{aligned}
$$

and

$$
\boldsymbol{n} \cdot(\boldsymbol{S} \cdot \boldsymbol{n})=0 .
$$

The tangential and bi-normal unit vectors, $\boldsymbol{t}$ and $\boldsymbol{b}$, at the surface have a similar orientation to those at the base. In this alignment the surface normal unit vector is $\boldsymbol{n}=\boldsymbol{t} \times \boldsymbol{b}$ pointing into the atmosphere. The boundary conditions for the horizontal velocity components can be obtained again by replacing the pressure (taken from Eqn (46)) in Eqns (44) and (45). They read as in Eqns (44) and (45), with $\beta^{2}=0$ and $c_{x}, c_{y}$ as well as $\boldsymbol{u}$ evaluated at the surface.

At the ice surface the mean annual air temperature, $\left.T\right|_{\mathrm{s}}=T_{\text {atm }}(x, y, t)$, is prescribed as the Dirichlet boundary condition.

\section{Calving front}

As for the upper and lower surface of the ice, a stress boundary condition is needed to solve the momentum equation (Eqn (8)). Since the convective transport of momentum across the calving front is very small, the traction is continuous at this boundary. Neglecting the atmospheric stresses, and assuming that dynamic stresses as well as viscous drag can be ignored, the pressure distribution in the ocean is hydrostatic. The dynamic boundary condition therefore reads as (Weis and others, 1999)

$$
\boldsymbol{S} \cdot \boldsymbol{n}=-p_{\mathrm{ocn}} \boldsymbol{n}, \quad \text { with } \quad p_{\mathrm{ocn}}= \begin{cases}-\rho_{\mathrm{sw}} g z & z<0 \\ 0 & \text { else, }\end{cases}
$$

where $p_{\text {ocn }}$ is the hydrostatic pressure in the ocean and $\rho_{\mathrm{sw}}$ is the density of sea water. We assume that the vertical shear stresses, $\sigma_{x z}, \sigma_{y z}$, in the ice shelf far away from the grounding line can be neglected, as well as bridging effects (pressure is cryostatic), and approximate the velocities at the calving front using the vertically integrated shallow-shelf approximation (e.g. MacAyeal and others, 1996).
Inflow

Along the lateral boundaries (lb) of the computational domain, Dirichlet boundary conditions for velocities are specified. We chose SIA velocities as (Payne and Dongelmans, 1997)

$$
\begin{aligned}
\boldsymbol{u}(\zeta)_{\mathrm{lb}}= & -2(\rho g)^{n} H^{n+1}\left|\operatorname{grad} z_{\mathrm{s}}\right|^{n-1} \operatorname{grad} z_{\mathrm{s}} \\
& \cdot \int_{0}^{\zeta} A\left(T^{*}\right) \zeta^{n} \mathrm{~d} \zeta+\boldsymbol{u}_{\mathrm{b},}
\end{aligned}
$$

where sliding at the base is neglected $\left(\boldsymbol{u}_{\mathrm{b}}=0\right)$. The horizontal heat transport is neglected (Payne, 1995; Payne and Dongelmans, 1997; Pattyn, 2003) and the temperatures are prescribed.

\section{SUBGLACIAL HYDROLOGY MODEL}

The temporal evolution of the water layer thickness, $H_{w}$, is given by the continuity equation

$$
\frac{\partial H_{\mathrm{w}}}{\partial t}=a_{\mathrm{b}}-\operatorname{div}\left(\overline{\boldsymbol{u}}_{\mathrm{w}} H_{\mathrm{w}}\right)
$$

where $\overline{\boldsymbol{u}}_{\mathrm{w}}$ is the depth-averaged water velocity vector (twodimensional). The subglacial water moves in the direction of decreasing hydraulic potential, $\Phi$, a function of elevation potential and water pressure. Assuming that basal water pressure is equal to the overlying ice pressure, the hydraulic potential can be written as (Shreve, 1972)

$$
\Phi=\rho_{\mathrm{w}} g z_{\mathrm{b}}+\bar{\rho} g H,
$$

where $\rho_{\mathrm{w}}$ is the density of water. The subglacial water is assumed to flow in a thin film of water (a few millimetres thick). In this thin-film model, water flow is assumed to be laminar; thus $\overline{\boldsymbol{u}}_{\mathrm{w}}$ becomes (Weertman, 1966, 1972)

$$
\overline{\boldsymbol{u}}_{\mathrm{w}}=-\frac{H_{\mathrm{w}}^{2}}{12 \mu_{\mathrm{w}}} \operatorname{grad} \Phi,
$$

where $\mu_{\mathrm{w}}$ is the viscosity of water.

It is further assumed that the timescales for the water flow are much smaller than the timescales for the ice flow, so the water system reaches steady state $\left(\partial H_{\mathrm{w}} / \partial t=0\right)$ in every time-step of the ice-flow model. At steady state, the basal melting rate must balance the water flux divergence and the steady water flux, $\psi_{\mathrm{w}}=\overline{\boldsymbol{u}}_{\mathrm{w}} H_{\mathrm{w}}$, can be obtained by integrating the basal melt rate over the whole drainage area, starting at the hydraulic head in the direction of the hydraulic potential gradient. We use different grid-based flux-routing schemes that are widely used in the literature (e.g. Le Brocq and others, 2009; Pattyn, 2010; Carter and Fricker, 2012) to perform this integration. The flux routing is based on the assumption that the outgoing water flux from an area is equal to the incoming flux plus the melt rate in the area. In contrast to the work of Le Brocq and others (2009) and Carter and Fricker (2012), where they used a prescribed basal melting rate, we compute the basal melt rate at every time-step. Hence, changes in the basal thermal regime, caused by changes in basal sliding conditions, feed back into the amount of meltwater available at the base.

We have implemented three different flux-routing schemes (Quinn and others, 1991; Budd and Warner, 1996; Tarboton, 1997) in our flow model that differ in the number of neighbours and in the direction of flow. An overview of the main characteristics of the three schemes is given by Le Brocq and others (2006). 


\section{BASAL SLIDING}

Basal sliding is described by a Weertman-type sliding law (Weertman, 1957, 1964):

$$
\boldsymbol{u}_{\mathrm{b}}=-C_{\mathrm{b}}\left|\tau_{\mathrm{b}}\right|^{p-1} \tau_{\mathrm{n}}^{-q} \tau_{\mathrm{b}}
$$

where

$$
\boldsymbol{u}_{\mathrm{b}}=\left.\left(\begin{array}{c}
\boldsymbol{t} \cdot \boldsymbol{u} \\
\boldsymbol{b} \cdot \boldsymbol{u}
\end{array}\right)\right|_{\mathrm{b}} \text { and } \tau_{\mathrm{b}}=\left.\left(\begin{array}{c}
\boldsymbol{t} \cdot(\boldsymbol{S} \cdot \boldsymbol{n}) \\
\boldsymbol{b} \cdot(\boldsymbol{S} \cdot \boldsymbol{n})
\end{array}\right)\right|_{\mathrm{b}}
$$

are the velocity and basal shear stress vectors in the basal plane and $\tau_{\mathrm{n}}=\left.\boldsymbol{n} \cdot(\boldsymbol{S} \cdot \boldsymbol{n})\right|_{\mathrm{b}} \approx \bar{\rho} g H$ is the basal normal pressure, taken as the ice overburden pressure. The stress and pressure exponents are chosen as $p=3$ and $q=2$ (Greve, 2005). The basal sliding parameter, $C_{b}$, depends on, for example, bed material and roughness, and is modified to allow sliding below the local pressure-melting point, $T_{\text {pmp }}$ (Budd and Jenssen, 1987; Hindmarsh and Le Meur, 2001; Greve, 2005; Pattyn and others, 2005):

$$
C_{\mathrm{b}}=f_{T} C_{\mathrm{b}}^{0}, \quad f_{T}=\exp \left[\nu\left(T-T_{\mathrm{pmp}}\right)\right],
$$

where the exponential decay, $\nu$ (sub-melt sliding parameter), measures the temperature range in which a significant amount of sliding is allowed below the pressure-melting point. According to Weertman's theory of sliding, the sliding velocity depends on the thickness of the basal water layer (Weertman, 1969; Weertman and Birchfield, 1982). We therefore extend the sliding law to account for the subglacial water layer thickness as

$$
C_{\mathrm{b}}=\left(1+f_{\mathrm{w}}\right) f_{T} C_{\mathrm{b}}^{0}, \quad f_{\mathrm{w}}=9\left[1-\exp \left(-\frac{H_{\mathrm{w}}}{H_{\mathrm{w}}^{0}}\right)\right],
$$

where $H_{\mathrm{w}}^{0}=1 \mathrm{~mm}$ is the typical scale of the layer thickness. The approach is similar to that of Johnson and Fastook (2002), but here the increase of sliding velocity due to basal water is limited to a factor of 10 , due to the exponential saturation function. We expect that if a sufficient water layer thickness is reached, more meltwater would not lead to additional sliding. In this study we take $C_{\mathrm{b}}^{0}$ as a constant (Table 1), assuming the same subglacial material and roughness throughout the whole model domain.

In the limit of the SIA, Eqn (52) would read as Dirichlet boundary conditions for the horizontal velocity components, since the bedrock is assumed to be horizontal for each position at the base, thus $\left(u_{\mathrm{b}}, v_{\mathrm{b}}\right)^{\top} \approx\left(\left.u\right|_{z_{\mathrm{b}}},\left.v\right|_{z_{\mathrm{b}}}\right)^{\top}$. In general the slope of the bedrock cannot be neglected. We therefore rewrite Eqn (52) as

$$
\boldsymbol{\tau}_{\mathrm{b}}=-\frac{1}{C_{\mathrm{b}}\left|\boldsymbol{\tau}_{\mathrm{b}}\right|^{p-1} \tau_{\mathrm{n}}^{-q}} \boldsymbol{u}_{\mathrm{b}}=-\beta^{2} \boldsymbol{u}_{\mathrm{b}}
$$

that can be used together with Eqn (53) to replace the righthand sides in Eqns (35) and (36). Due to the nonlinear coupling between the velocity and the shear stress at the base in Eqn (56), the velocity field needs to be computed in an iterative way. The basal sliding parameter, $\beta^{2}$, varies over time, depending on the local subglacial water layer thickness and ice temperature, as well as basal shear and normal stresses.

\section{NUMERICAL SOLUTION SCHEME}

Although we only consider a fixed geometry in this paper, we present the full solution scheme of the model, for the sake of completeness. The equations are discretized on a colocated grid (thus all variables are located at the same grid position) that is, in general, non-equidistant in the vertical and horizontal directions using a second-order finite-difference approximation (Payne and Dongelmans, 1997; Pattyn, 2002). In the terrain-following coordinate system, the grid is given by $N=N_{\xi} \times N_{\eta} \times N_{\zeta}$ gridpoints connected through orthogonal lines.

Due to the nonlinear coupling of the horizontal velocity fields, a successive substitution of $u\left(\xi_{i}, \eta_{j}, \zeta_{k}\right)=u_{i, j, k}$ and $v\left(\xi_{i}, \eta_{j}, \zeta_{k}\right)=v_{i, j, k}$ is used. The finite-difference forms of the transformed differential equations (Eqns (20) and (21) together with their boundary conditions, Eqns (39) and (40) evaluated at the upper and lower surfaces) can be written in matrix-vector notation as

$$
\begin{aligned}
& \boldsymbol{A}\left(\mu^{l}\right) \boldsymbol{U}^{*}=\boldsymbol{b}\left(v^{l}, w^{\prime}, R_{z z^{\prime}}^{l} \cdots\right) \\
& \boldsymbol{C}\left(\mu^{l}\right) \boldsymbol{V}^{*}=\boldsymbol{d}\left(u^{l}, w^{\prime}, R_{z z^{\prime}}^{l} \cdots\right)
\end{aligned}
$$

where $I$ is the iteration index, and $\boldsymbol{U}^{*}=\left(u_{1}^{*}, \cdots, u_{N}^{*}\right)^{\top}$, $\boldsymbol{V}^{*}=\left(v_{1}^{*}, \cdots, v_{N}^{*}\right)^{\top}$ are the preliminary solutions based on the previous iteration. The new velocity vector is obtained by an under-relaxation scheme,

$$
\boldsymbol{U}^{l+1}=\alpha \boldsymbol{U}^{*}+(1-\alpha) \boldsymbol{U}^{\prime},
$$

and analogously for $\boldsymbol{V}^{l+1}$, where $\alpha=0.8$ (Pimentel and others, 2010) is the relaxation parameter. During each iteration, I, of the nonlinear iteration scheme we solve Eqns (57) and (58) using an iterative linear solver for large sparse matrices (ILU0-GMRES; Saad, 2003). Based on the new estimates for the horizontal velocity field we then compute the vertical velocity, $w$, in each ice column using Eqns (22) and (41) in their discretized forms and a direct band diagonal solver (Press and others, 1992). A very similar approach is used for $R_{z z}$ (Eqn (23)). Convergence of the linear solver is assumed if

$$
\left\|\boldsymbol{A} \boldsymbol{U}^{*}-\boldsymbol{b}\right\| /\|\boldsymbol{b}\|<\epsilon_{\text {res, }}
$$

and analogously for $\boldsymbol{V}^{*}$. We stop the nonlinear iteration process if

$$
\max \left(\frac{\left\|\boldsymbol{U}^{\mathrm{l}+1}-\boldsymbol{U}^{\prime}\right\|_{2}}{\left\|\boldsymbol{U}^{\prime}\right\|_{2}}, \frac{\boldsymbol{V}^{\mathrm{I}+1}-\boldsymbol{V}^{\prime} \|_{2}}{\left\|\boldsymbol{V}^{\prime}\right\|_{2}}\right)<\epsilon_{\mathrm{rel}}
$$

or

$$
\max \left(\left\|\boldsymbol{U}^{l+1}-\boldsymbol{U}^{\prime}\right\|_{\infty},\left\|\boldsymbol{V}^{l+1}-\boldsymbol{V}^{\prime}\right\|_{\infty}\right)<\epsilon_{\mathrm{abs}} .
$$

At this point the Stokes equations are solved for a given temperature and geometry.

The advective terms, $u \partial T / \partial \xi, v \partial T / \partial \eta$ and $w^{*} \partial T / \partial \zeta$, in Eqn (26) are discretized using the hybrid difference scheme (HDS; Spalding, 1972) which switches the discretization between the second-order central difference scheme (CDS) and the first-order upwind difference scheme (UDS) according to the local cell Peclet number. Thus $\mathcal{L}^{\mathrm{HDS}}=$ $s \mathcal{L}^{\mathrm{UDS}}+(1-s) \mathcal{L}^{\mathrm{CDS}}$, where $\mathcal{L}^{\mathrm{HDS}}$ is the one-dimensional spatial discretization operator of the advective terms and $s$ is a weighting factor depending on the Peclet number, $P e$, as

$$
s(P e)= \begin{cases}0, & P e<1.9 \\ 10(P e-1.9), & 1.9 \leq P e<2.0 \\ 1, & P e \geq 2.0\end{cases}
$$

The HDS is applied to all spatial dimensions and avoids numerical instabilities arising from the CDS for high velocities $(P e>2)$; it also limits the amount of artificial diffusion due to UDS for low velocities (small $P$ e). The conductive term, $K \partial^{2} T / \partial \zeta^{2}$, in Eqn (26) is discretized using 
a second-order central difference scheme for the second derivative, denoted here as CDS2. Expressions for the discretization schemes (CDS, UDS and CDS2) on nonequidistant grids can be found in the literature (e.g. Ferziger and Perić, 2002). The time-stepping is performed using the semi-implicit Crank-Nicolson scheme, where the temperature at the next time-step depends on the temperature, the source term (Eqn (29)) and the material properties, $c_{p}$ and $\kappa$, at the actual time-step. We use a constant time-step of 1 year and an asynchronous coupling, where the temperature module is run repeatedly for every time-step coupled to the ice-dynamic module (Stokes) every fifth step (1:5 coupling). The Crank-Nicolson scheme allows much larger time-steps, but we found an effective time-step of 1 year to be a good compromise between temporal resolution and computational time. The smaller time-steps in the temperature module can further be seen as a sub-iteration scheme to resolve the temperature dependency of the thermal diffusivity and heat capacity.

The hydrological component of the numerical model is coupled to the temperature at the end of each time-step. Basal ice temperatures, the resulting basal melt rates and the ice geometry from the flow model are used as input for the hydrology module, which computes the steady-state waterlayer thickness as an input quantity for the ice-dynamic module.

Although ice-thickness evolution is already implemented in TIM-FD ${ }^{3}$, and has been tested in the Ice Sheet Model Intercomparison Project for Higher-Order Models (ISMIPHOM; Pattyn and others, 2008) and also in the Marine IceSheet Model Intercomparison Project (MISMIP3d; Pattyn and others, 2013), all simulations performed in this study are based on a fixed geometry. Several studies (e.g. Durand and others, 2009; Gladstone and others, 2010; Pattyn and others, 2012), based on idealized geometries, have shown the importance of a very fine horizontal resolution of the grounding zone (transition between grounded and floating ice) to capture the ice evolution well in these areas. Running the model in the geometry evolution mode would therefore require very high-resolution data of the bedrock topography under the ice and, even more difficult to observe, the bedrock topography under the floating ice shelves.

\section{STUDY AREA}

The study area is located at the margin of western Dronning Maud Land and the eastern part of Oates Land, Antarctica, at $71-78.5^{\circ} \mathrm{S}, 2-30^{\circ} \mathrm{W}$ (Fig. 1). The region consists of the Brunt Ice Shelf (BIS) in the southwest, the Riiser-Larsen Ice Shelf (RLIS) in the northeast and their drainage areas. The BIS and the RLIS are separated by the Stancomb-Wills Ice Tongue (SWIT), the floating extension of the Stancomb-Wills Ice Stream (SWIS) that crosses the Caird Coast (CC).

The BIS and SWIT areas are highly heterogeneous: between the relatively thick and fast SWIT and the considerably thinner and slower BIS, an area exists that is made up of a discontinuous mass of ice blocks that have calved at the grounding line and are frozen together by a melange of sea ice, small icebergs and accumulated snow (Hulbe and others, 2005; Humbert and others, 2009). Two major rift systems evolve under the stress regimes between the SWIT and the RLIS (rift 1) and between the SWIT and the BIS (rift 2). In the rift areas the ice is thinner and formed of a mechanically weaker mixture of meteoric and mainly

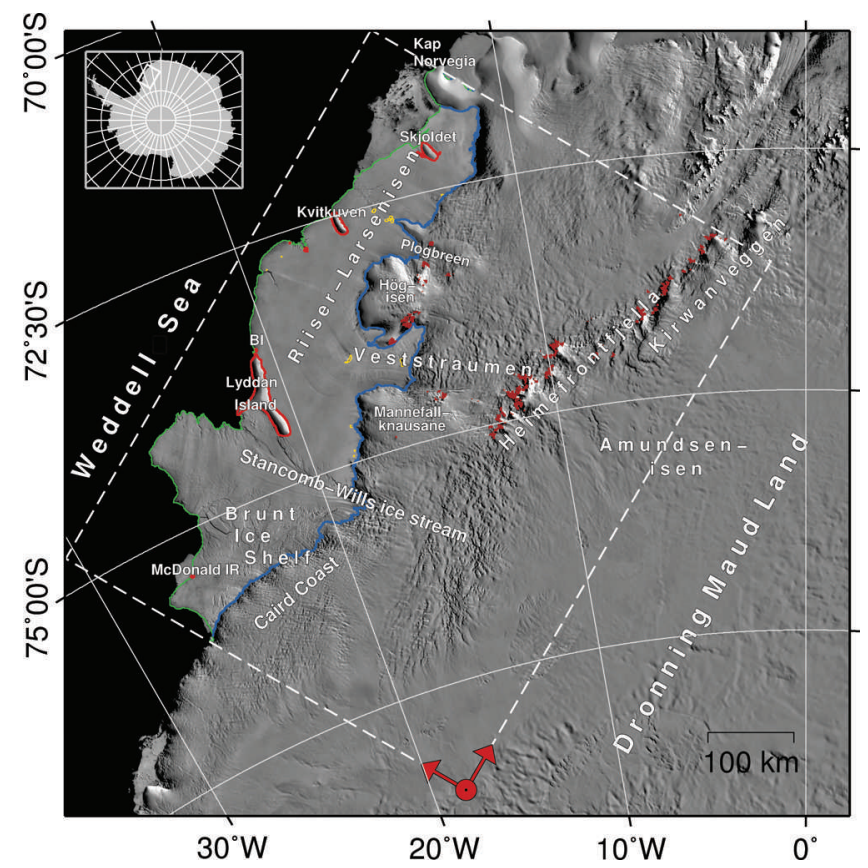

Fig. 1. Map of the Brunt Ice Shelf, the Riiser-Larsen Ice Shelf and the adjacent grounded ice parts of western Dronning Maud Land, including feature names and the outline of the model domain (dashed line). Underlain is a Mosaic of Antarctica (MOA) image (Haran and others, 2005) acquired between late 2003 and early 2004. The red arrows in the lower part of the figure indicate the origin and orientation of the local coordinate system used in this study. Different glaciological units are marked with coloured lines. The inset shows the location of the area at the eastern margin of the Weddell Sea, Antarctica.

marine ice. The margin of the BIS is pinned by the relatively small McDonald Ice Rise (Humbert and others, 2009).

The RLIS area is relatively homogeneous compared with the BIS/SWIT area and contains three major ice rises near the calving front (Lyddan Island, Kvitkuven and Skjoldet). The ice shelf in this area is further stabilized by several small pinning points inside the ice shelf, as well as near the calving front. Further important features are the ice streams Plogbreen and Veststraumen, that are responsible for most of the mass discharge over the grounding line in this region. A grounded area (ice rise/ice rumple) is located in Veststraumen at about $74^{\circ} \mathrm{S}, 17.5^{\circ} \mathrm{W}$ and diverts the flow as can be seen on satellite images (Fig. 1). The two ice streams are separated by the dome-shaped Högisen.

\section{Model set-up}

The study area is relatively well covered by satellite altimetry measurements of surface elevation from the Ice, Cloud and land Elevation Satellite (ICESat)/Geoscience Laser Altimeter System (GLAS) (Zwally and others, 2005). Data from 2003 were used, which cover approximately the same time period as the Mosaic of Antarctica (MOA) image (November 2003 and February 2004; Haran and others, 2005). Ellipsoid heights were converted to freeboard heights using the World Geodetic System 1984 (WGS84) version of the Earth Gravitational Model EGM2008 (Pavlis and others, 2008). Ice-thickness datasets from expeditions, which are collected in the BEDMAP database (Lythe and others, 2001), have to be assembled. We included additional airborne electromagnetic radar (EMR) measurements of the ice thickness, 


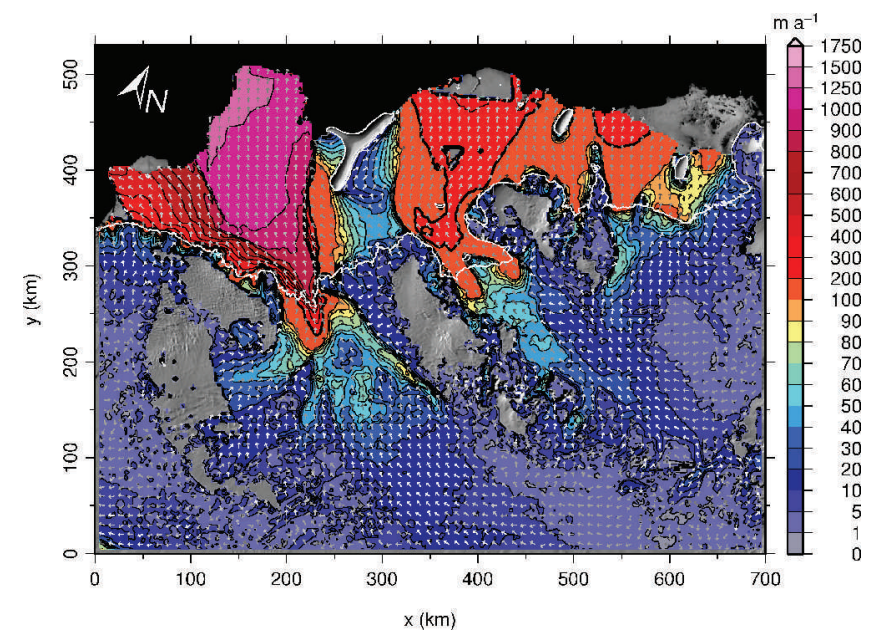

Fig. 2. Surface velocities derived from satellite radar interferometry, mainly from Advanced Land Observing Satellite (ALOS) Phased Array-type L-band synthetic aperture radar (PALSAR) measured in 2007, 2008 and 2009 (Rignot and others, 2011).

taken by the Alfred Wegener Institute between 1994 and 2008 (Steinhage and others (2001) give details of the method) as well as electromagnetic radiation (EMR) measurements provided by the British Antarctic Survey (personal communication from D.G. Vaughan, 2009). Older Russian EMR measurements taken in 1988/89 are used only for the grounded part of the ice and only in areas where no other data are available.

Line segments of the calving front and grounding-line position were manually digitized by visual inspection of the MOA image and existing datasets (Antarctic Digital Database (ADD), MOA) as well as surface elevations and TerraSAR-X images. Small pinning points with an area less than the grid size were manually increased to be represented by at least one gridpoint. In the freely floating part $(5 \mathrm{~km}$ away from the grounding line) surface elevations from ICESat/GLAS, together with the floating conditions, are used to compute the ice thickness. This was necessary because only a few ice-thickness profiles exist in the floating areas. The required distribution of $\bar{\rho}(x, y)$ was computed from locations where surface and ice-thickness measurements were available.

Previous model studies of the BIS-SWIT system have shown that the effect of increased damage, and therefore reduced stiffness in the rift areas, needs to be incorporated in simulations to better approximate the observed flow field (Hulbe and others, 2005; Humbert and others, 2009; Khazendar and others, 2009). We therefore reduce the associated stress-enhancement factors, $E_{\mathrm{s}}=E^{-1 / n}$, to $E_{\mathrm{s}}=0.3$ at rift 1 and $E_{\mathrm{s}}=0.1$ at rift 2 . The positions of the two major rifts are the same as given by Humbert and others (2009). Areas of ice melange located between the SWIT and the RLIS and between the SWIT and the BIS are assumed to be less stiff $\left(E_{\mathrm{s}}=0.5\right)$ than the meteoric ice areas. For all other areas (grounded and floating) we use a constant enhancement factor of $E_{\mathrm{s}}=1.0$.

Annual mean temperatures described by Comiso (2000a), were used to provide the surface temperature field together with the surface mass balance (Van de Berg and others, 2006) and are applied at the ice upper surface. At the base the basal geothermal heat flux of Shapiro and Ritzwoller (2004) is used, unless stated otherwise. These boundary conditions were taken from the ALBMAPv1 dataset (Le Brocq and others, 2010) and interpolated to the used grid positions.

Under the assumption of a constant geometry $(\partial H / \partial t=0)$, the basal mass balance, $a_{b}$, under the ice shelf is derived from the ice-thickness evolution (Eqn (32)) and accounts for the divergence of the horizontal ice flux, and the surface mass balance, $a_{\mathrm{s}}$. For the free-floating ice the vertical mean velocity equals the surface velocity, since no vertical shearing occurs, so the basal mass balance can be estimated from observed velocities (Humbert, 2010; Neckel and others, 2012). Surface velocities derived from interferometric synthetic aperture radar (InSAR) (Rignot and others, 2011) are used for this purpose (Fig. 2). Short distance variations arising from strong ice-thickness gradients (e.g. ice melange area) or velocity gradients between fast- and slow-flowing units (shear margins) were spatially averaged, in order to obtain a smooth distribution of $a_{b}$.

In general, the thermodynamic conditions at the ice/ ocean interface are very complex and depend on, for example, currents and vertical mixing in the ocean. Boundary conditions at the ice-shelf base should therefore be derived from an ocean model or observations. An adequate method to quantify surface fluxes and subsequent ocean melting rates at the ice/ocean interface (Holland and Jenkins, 1999) would require a realistic simulation of the sub-ice-shelf ocean circulation, based on a precisely known geometry and temporal evolution of the ice-shelf cavity, to accurately capture the basal melt rate under the ice shelf (Schodlok and others, 2012). Our steady-state estimate of $a_{b}$ shows highest melt rates close to the grounding line at the SWIT (11 mw.e. $\mathrm{a}^{-1}$ ) and Veststraumen ( $5 \mathrm{mw}$.e. $\mathrm{a}^{-1}$ ) and close to the calving front of the SWIT $\left(5 \mathrm{mw}\right.$.e. $\left.\mathrm{a}^{-1}\right)$. Refreezing rates up to $4 \mathrm{~m}$ w.e. $\mathrm{a}^{-1}$ occur mainly in the small areas between individual icebergs in the melange area between the BIS and the SWIT. The estimated total average is $a_{b}=-0.19 \pm 1.1 \mathrm{~m}$ w.e. $\mathrm{a}^{-1}$ (net melting) and is significantly lower than the simulated melt rates of Thoma and others (2006; $0.88 \mathrm{~m} \mathrm{a}^{-1}$ ) or Timmermann and others (2012; $\left.0.94 \mathrm{~m} \mathrm{a}^{-1}\right)$.

The final model domain consists of $N_{\xi}=281$ by $N_{\eta}=213$ horizontal nodes forming a $2.5 \mathrm{~km} \times 2.5 \mathrm{~km}$ grid, and $N_{\zeta}=21$ unequally spaced vertical layers. Model parameters and the used constants are summarized in Table 1.

\section{RESULTS}

\section{Spin-up and cyclic behaviour}

The model was run for $200 \mathrm{ka}$ without basal sliding, under the present-day climate, to achieve a steady-state temperature and velocity distribution. Initial temperatures for the spin-up were chosen to lead to a cold ice base in the whole domain. To illustrate the thermal evolution during the model spin-up $\left(\mathrm{SU}_{\mathrm{t}}\right)$, the mean ice temperature and the temperate ice area fraction (TIAF) are shown in Figure 3 (red and black curves). Approximately $28 \%$ of the grounded area is at the pressure-melting point, and a mean ice temperature of $-19^{\circ} \mathrm{C}$ is reached at the end of the spin-up. After $\sim 100 \mathrm{ka}$, variations in temperature and TIAF become small, but never vanish. The observed period is $\sim 2 \mathrm{ka}$, with varying amplitudes in a small band of $\pm 0.1^{\circ} \mathrm{C}$ and $\pm 0.5 \%$ TIAF. If we compare the thermal evolution of this spin-up with a similar simulation $\left(\mathrm{SU}_{\mathrm{c}}\right)$, where we used the cold ice rheology everywhere, the oscillations of the ice temperature 


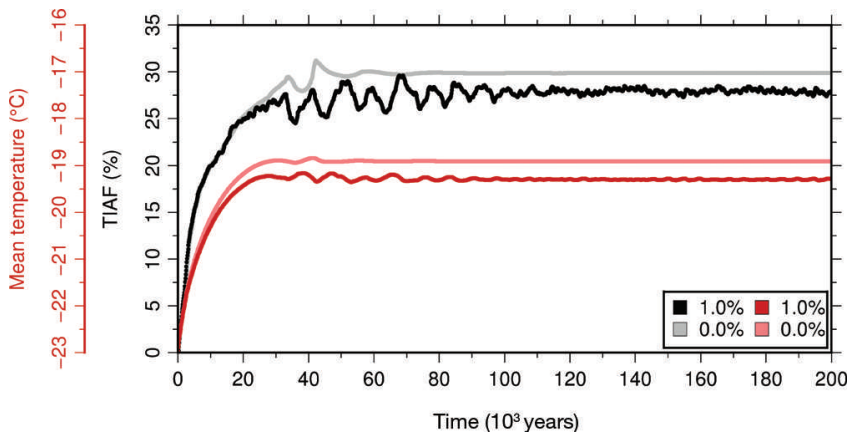

Fig. 3. Temporal evolution of the mean pressure-corrected ice temperature (red) and the temperate ice area fraction at the base (TIAF, black) during the 200 ka spin-up using $1 \%$ water content where the ice is at pressure-melting point $\left(\mathrm{SU}_{\mathrm{t}}\right)$ and the corresponding quantities in pale red and grey for the cold ice rheology applied everywhere $\left(\mathrm{SU}_{\mathrm{c}}\right)$.

and also of the TIAF vanish after $\sim 100 \mathrm{ka}$ (pale red and grey curves in Fig. 3). The oscillations in $\mathrm{SU}_{\mathrm{t}}$ are therefore related to feedbacks between the thermal and the dynamical subsystems and need to be considered in the later analysis. The mean temperature and TIAF at the end of $\mathrm{SU}_{\mathrm{C}}$ are slightly higher than in $\mathrm{SU}_{\mathrm{t}}$.
The distributions of the basal homologous temperature and the resulting basal melt rates at the end of the spin-up, $\mathrm{SU}_{\mathrm{t}}$, are shown in Figure 4 (upper row).

Temperate areas are mainly located close to the grounding line and in the ice-stream areas. These regions are subject to basal melt rates of a few centimetres per year, with largest values $\left(>10 \mathrm{~cm} \mathrm{a}^{-1}\right)$ close to the grounding line of the SWIS. At the outer margins of the temperate ice areas some grid nodes also show very low freeze-on rates. Temperate ice areas with significant melt generally coincide with areas of ice-stream flow. The simulated cold area in the SWIS at $x \approx 270 \mathrm{~km}, y \approx 200 \mathrm{~km}$ is located where observed surface velocities (Fig. 2) are very low. In our simulations the location of this area, hereinafter referred to as a 'sticky spot', varies over time and is, together with an area near the grounding line of $\mathrm{CC}$, predominantly responsible for the fluctuations shown in Figure 3. To eliminate the effect of small temporal variations and to investigate the mean behaviour over time, we compare model results as the temporal mean of the last $10 \mathrm{ka}$, unless stated otherwise. We further vary the basal geothermal heat flux, the stressenhancement factor and the inflow velocity at the domain lateral boundary independently, to illustrate the model sensitivity to the standard parameters used in this study. The results are summarized in Table 2.
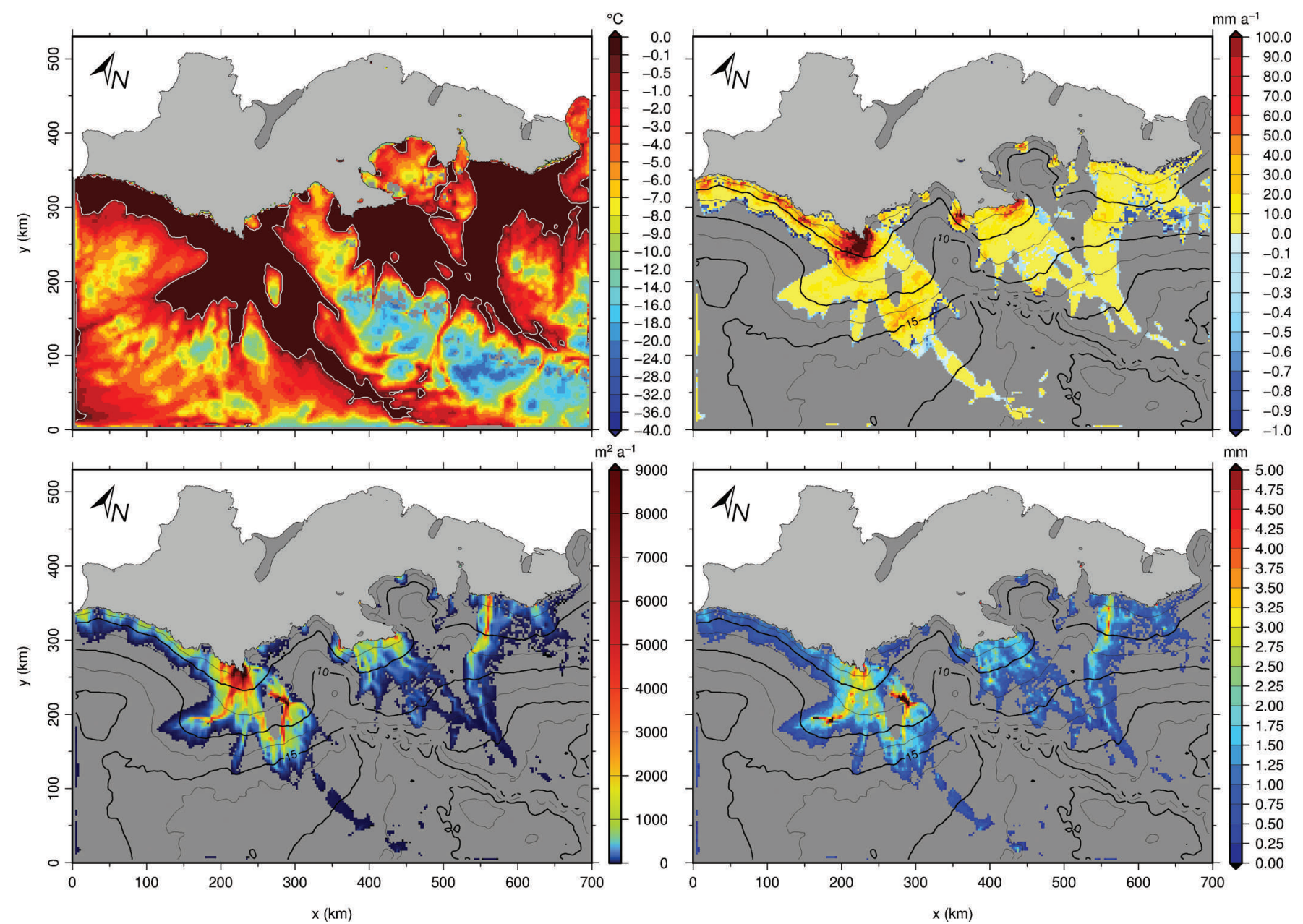

Fig. 4. The homologous temperature at the base (upper left) and basal melt rate (upper right) at the end of the 200 ka spin-up simulation, $\mathrm{SU}_{\mathrm{t}}$ are used the compute the basal water flux (lower left) and the basal water layer thickness (lower right). Here we have used the Budd and Warner (1996) flux-routing scheme, $\mathrm{BW}_{\mathrm{t}}$, as an example. Contours of the hydropotential are overlaid as thick black curves every $5 \mathrm{MPa}$. In the upper left panel the $-0.1^{\circ} \mathrm{C}$ contour is shown in light grey. 
Table 2. Comparison of the temperate ice area fraction (TIAF) at the base, the area mean basal homologous temperature, $T_{\mathrm{b}}^{*}$, the volume mean velocity magnitude, $|u|$, and the mean surface velocity difference, $\Delta u_{\mathrm{s}}=u_{\mathrm{sim}}-u_{\mathrm{obs}}$, if $u_{\mathrm{obs}} \geq 5 \mathrm{~m} \mathrm{a}^{-1}$, and the correlation, $r$, between the observed, $u_{\text {obs, }}$ and simulated, $u_{\text {sim, }}$ surface velocities for different spin-up simulations without basal sliding. (All quantities except the mean velocity are computed for the grounded ice part only)

\begin{tabular}{lrrrrr}
\hline Experiment & TIAF & \multicolumn{1}{c}{$T_{\mathrm{b}}^{*}$} & $|u|$ & \multicolumn{1}{c}{$\Delta u_{\mathrm{s}}$} & $r$ \\
& $\%$ & \multicolumn{1}{c}{${ }^{\circ} \mathrm{C}$} & $\mathrm{m} \mathrm{a}^{-1}$ & \multicolumn{1}{c}{$\mathrm{m} \mathrm{a}^{-1}$} & \\
\hline Spin-up, $\mathrm{SU}_{\mathrm{t}}$ & 27.9 & -4.2 & 41.4 & $2 \pm 23$ & 0.82 \\
Spin-up, $\mathrm{SU}_{\mathrm{c}}$ & 29.9 & -4.2 & 35.9 & $-5 \pm 20$ & 0.80 \\
$E=1(\mathrm{const})$ & 28.3 & -4.2 & 37.6 & $2 \pm 22$ & 0.83 \\
$q_{\mathrm{geo}}=40 \mathrm{~mW} \mathrm{~m}^{-2}$ & 15.3 & -6.8 & 36.9 & $-4 \pm 20$ & 0.84 \\
$q_{\mathrm{geo}}=60 \mathrm{~mW} \mathrm{~m}^{-2}$ & 35.7 & -3.4 & 43.3 & $4 \pm 23$ & 0.82 \\
$q_{\mathrm{geo}}=80 \mathrm{~mW} \mathrm{~m}^{-2}$ & 56.4 & -1.8 & 46.5 & $8 \pm 24$ & 0.82 \\
$u_{\mathrm{lb}}=0 \mathrm{~m} \mathrm{a}^{-1}$ & 28.6 & -4.2 & 41.0 & $2 \pm 22$ & 0.83 \\
$u_{\mathrm{lb}}=0.5 \times \mathrm{SIA}$ & 28.3 & -4.2 & 41.3 & $2 \pm 22$ & 0.83 \\
$u_{\mathrm{lb}}=2.0 \times \mathrm{SIA}^{27.6}$ & 27.6 & -4.3 & 41.4 & $2 \pm 23$ & 0.82 \\
\hline
\end{tabular}

We find that the model results are not sensitive to the inflow velocities in the range of zero velocity up to doubled SIA velocities. The lateral boundaries mostly affect gridpoints close to the boundary, since the velocities in that area (far away from the grounding line) are generally low. Since the horizontal advective heat transport for low velocities is not very efficient, we assume a low sensitivity to the prescribed temperatures at the margin. The area of temperate ice at the base is very sensitive to the applied basal heat flux and ranges between $15 \%$ and $56 \%$ for the 40 and $80 \mathrm{~mW} \mathrm{~m}^{-2}$ simulation, respectively. The TIAF of the standard spin-up is below the value given by the $60 \mathrm{~mW} \mathrm{~m}^{-2}$ simulation. This value corresponds well with the mean geothermal heat flux of $56 \pm 4 \mathrm{~mW} \mathrm{~m}^{-2}$ in the model domain for the Shapiro and Ritzwoller (2004) dataset that we apply in this study. Mostly the mountainous areas do not reach the pressure-melting point in the $80 \mathrm{~mW} \mathrm{~m}^{-2}$ simulation because of the very low surface temperatures and the relatively thin ice cover.

Differences in the mean temperatures (not shown here) between all spin-up simulations are small. They vary between $-18.9^{\circ} \mathrm{C}\left(\mathrm{SU}_{\mathrm{c}}\right)$ and $-19.6^{\circ} \mathrm{C}\left(80 \mathrm{~mW} \mathrm{~m}^{-2}\right)$ and are therefore only useful to characterize the transient behaviour during the spin-up, but not to compare simulation results. This is also found for the mean velocity that varies between $35.9 \mathrm{~m} \mathrm{a}^{-1}\left(\mathrm{SU}_{\mathrm{c}}\right)$ and $46.5 \mathrm{~m} \mathrm{a}^{-1}\left(80 \mathrm{~mW} \mathrm{~m}^{-2}\right)$ with a value of $41.4 \mathrm{~m} \mathrm{a}^{-1}$ for the standard spin-up.

The simulation performed with a constant enhancement factor, $E=1$, for the whole modelling domain shows only a minor reduction in the mean ice velocity. This is due to a higher buttressing effect of the SWIT, since no shearing or decoupling at the two major rifts is considered in this model run. The mean surface velocity differences, $\Delta u_{\mathrm{s}}=$ $u_{\text {sim }}-u_{\text {obs, }}$ where $u_{\text {obs }}$ are the velocities given by Rignot and others (2011) (Fig. 2), are between -5 and $+8 \mathrm{~m} \mathrm{a}^{-1}$ and have standard deviation (stddev) of $\sim 20 \mathrm{~m} \mathrm{a}^{-1}$. The correlation between observed, $u_{\text {obs, }}$ and simulated, $u_{\text {sim }}$, surface velocities in the grounded ice area is $\sim 0.8$ for all simulations.

\section{Reference simulation}

Starting from the standard spin-up simulation, the reference simulation $\left(R E F_{t}\right)$ is integrated for another $30 \mathrm{ka}$, where we

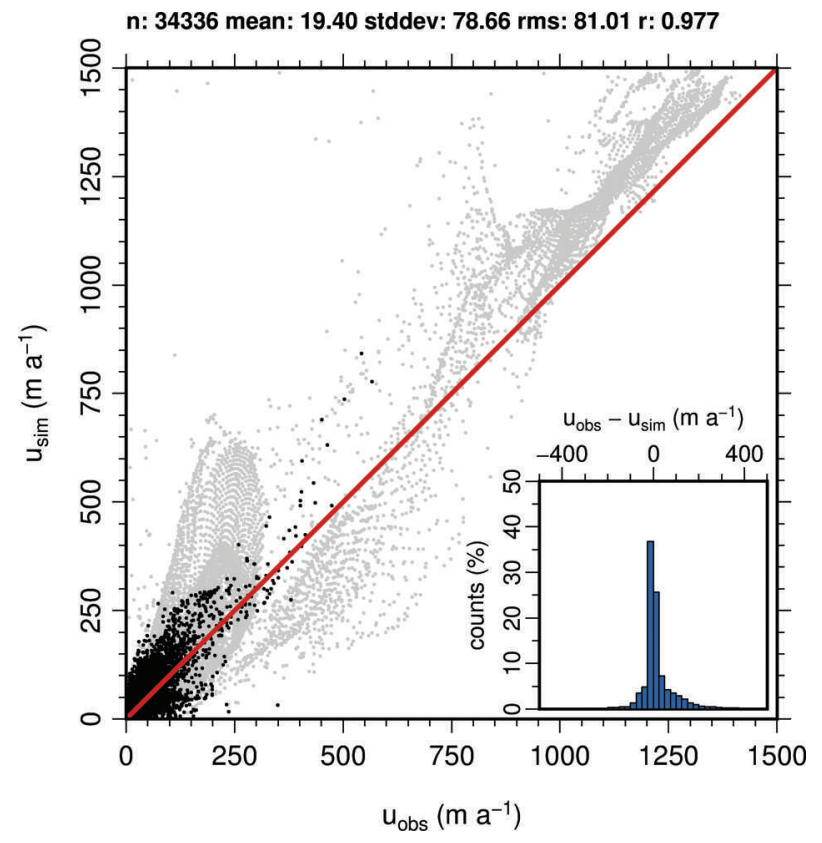

Fig. 5. Scatter plot of the simulated, $u_{\text {sim, }}$ and observed, $u_{\text {obs, }}$ surface velocities separated for the floating (grey) and the grounded (black) gridpoints. The inset shows the histogram of the differences between observed and simulated velocities using bins of 25 . The statistical quantities quoted in the figure apply to the grounded and floating part of the ice. Simulated velocities are averaged over the last $10 \mathrm{ka}$ of model integration.

allow for basal sliding computed with the Weertman-type sliding law without basal water $\left(f_{\mathrm{w}}=0\right.$ in Eqn (55)). In addition to $\mathrm{REF}_{\mathrm{t}}$ we continue the spin-up without changes in the set-up in the control simulation $\left(\mathrm{CON}_{\mathrm{t}}\right)$ to distinguish between sliding- and deformation-related processes.

A direct comparison of the simulated surface velocities, $u_{\text {sim, }}$ and observed velocities, $u_{\text {obs, }}$ is shown in Figure 5 for all grounded and floating gridpoints. The simulated velocities are slightly higher than the observed velocities. The mean difference is $19.4 \mathrm{ma}^{-1}\left( \pm 78.7 \mathrm{ma}^{-1}\right.$ stddev $)$ and the overall correlation is very high $(r=0.98)$. We compare the velocities only where the observed velocities are $\geq 5 \mathrm{ma}^{-1}$, since the very low observed velocities show a large spread in magnitude and direction (cf. Fig. 2). If we compare only the grounded points, the number of observations is reduced from 34366 to 22103 gridpoints and the mean difference reduces to $2.35 \mathrm{~m} \mathrm{a}^{-1}\left( \pm 22.2 \mathrm{~m} \mathrm{a}^{-1}\right.$ stddev). The correlation between observed and simulated velocities reduces to $r=0.83$ but is still high (Table 3 ).

The simulated basal homologous temperatures, the basal sliding parameter, $\beta^{2}$, the basal sliding velocities and the surface velocities are shown in the left column of Figure 6 , from top to bottom. As the sticky spot moves along the same path again and again it is not visible as such in the $10 \mathrm{ka}$ averages. The modelled sliding velocities are relatively low because of the low sliding parameter, $C_{\mathrm{b}}^{0}$. Highest sliding velocities $\left(\sim 25 \mathrm{~m} \mathrm{a}^{-1}\right)$ occur close to the grounding line at $\mathrm{CC}$, and in the southwestern part of Veststraumen, where geometry gradients and thus basal shear stresses reach their maximum. In general, sliding in the model occurs where the known ice streams are located. Only a few areas close to the grounding line are not sliding due to the low basal temperature (e.g. at Högisen, Mannefallknausane, and northeast of Plogbreen). High values for the basal sliding parameter, $\beta^{2}$ 

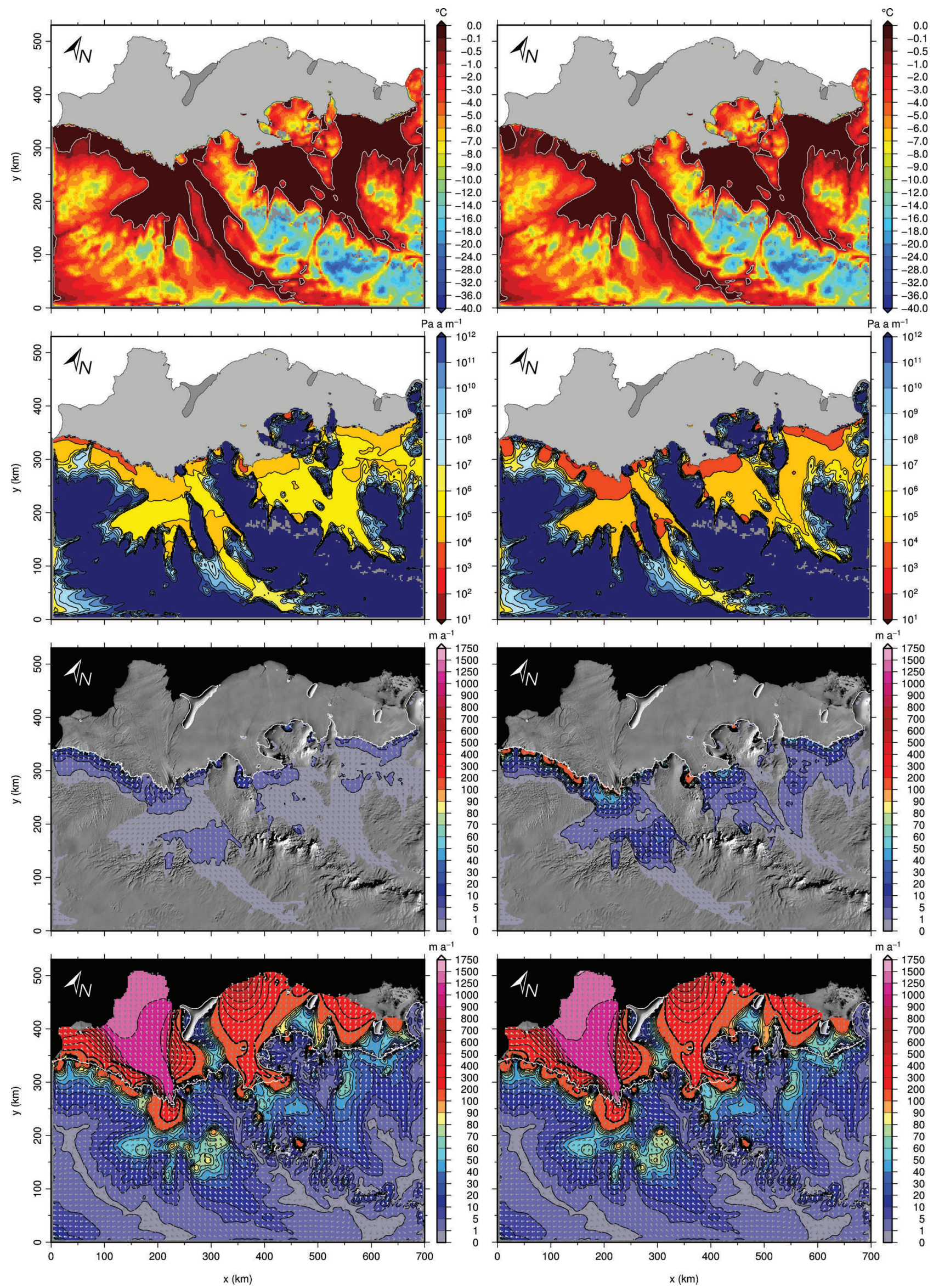

Fig. 6. Comparison of the reference, $\mathrm{REF}_{\mathrm{t}}$, simulation (left column) with sliding including Budd and Warner (1996), BW $\mathrm{W}_{\mathrm{t}}$, flux routing (right column) as temporal mean of the last $10 \mathrm{ka}$ at the end of the sliding experiment. From top to bottom: basal homologous temperature; sliding parameter, $\beta^{2}$; basal velocity (if $>10^{-3} \mathrm{ma}^{-1}$ ) and surface velocity. The velocity is represented as magnitude (colour-coded) and flow direction (arrows). The $-0.1^{\circ} \mathrm{C}$ temperature contour is shown in light grey in the uppermost panels. In the lowermost panels the $200 \mathrm{ma}^{-1}$ contour is drawn as a thick black curve on top of the other contours. 
Table 3. The mean surface velocity difference $\left(\Delta u_{\mathrm{s}}=u_{\mathrm{sim}}-u_{\mathrm{obs}}\right.$, if $\left.u_{\text {obs }} \geq 5 \mathrm{~m} \mathrm{a}^{-1}\right)\left(\mathrm{m} \mathrm{a}^{-1}\right)$, the standard deviation, stddev $\left(\mathrm{m} \mathrm{a}^{-1}\right)$, and the correlation, $r$, between the observed, $u_{\text {obs, }}$, and simulated, $u_{\text {sim }}$, surface velocities are given for all sliding simulations. Quantities are calculated for the grounded ice only (gr.) and for the entire domain (all) averaged over the last $10 \mathrm{ka}$ model integration

\begin{tabular}{|c|c|c|c|c|c|c|}
\hline \multirow[t]{2}{*}{ Experiment } & \multicolumn{2}{|c|}{$\operatorname{mean}\left(\Delta u_{\mathrm{s}}\right)$} & \multicolumn{2}{|c|}{$\operatorname{stddev}\left(\Delta u_{\mathrm{s}}\right)$} & \multicolumn{2}{|c|}{$r$} \\
\hline & gr. & all & gr. & all & gr. & all \\
\hline $\mathrm{CON}_{\mathrm{c}}$ & -4.91 & 3.77 & 19.72 & 72.12 & 0.792 & 0.976 \\
\hline $\operatorname{REF}_{\mathrm{c}}$ & -4.38 & 5.41 & 19.68 & 71.21 & 0.794 & 0.977 \\
\hline $\mathrm{BW}_{\mathrm{C}}{ }^{*}$ & -1.67 & 15.54 & 22.40 & 71.80 & 0.775 & 0.980 \\
\hline $\mathrm{QU}_{\mathrm{c}}^{\dagger}$ & -1.68 & 15.39 & 22.34 & 71.70 & 0.776 & 0.980 \\
\hline $\mathrm{TA}_{c^{\ddagger}}^{\ddagger}$ & -1.86 & 14.67 & 22.09 & 71.23 & 0.778 & 0.980 \\
\hline $\mathrm{CON}_{\mathrm{t}}$ & +2.12 & 18.24 & 22.17 & 79.00 & 0.828 & 0.977 \\
\hline $\mathrm{REF}_{\mathrm{t}}$ & +2.35 & 19.40 & 22.22 & 78.66 & 0.831 & 0.977 \\
\hline $\mathrm{BW}_{\mathrm{t}}$ & +4.17 & 25.72 & 25.45 & 80.72 & 0.826 & 0.979 \\
\hline $\mathrm{QU}_{\mathrm{t}}$ & +4.21 & 25.66 & 25.43 & 80.38 & 0.826 & 0.979 \\
\hline $\mathrm{TA}_{\mathrm{t}}$ & +4.19 & 25.35 & 25.27 & 80.19 & 0.827 & 0.979 \\
\hline
\end{tabular}

*Budd and Warner (1996). ${ }^{\dagger}$ Quinn and others (1991). ${ }^{\ddagger}$ Tarboton (1997).

(dark blue in Fig. 6), represent areas of high basal resistance, controlled by the basal temperatures, that do not lead to significant sliding velocities even in areas of sub-melt sliding (mostly in light blue). Along the grounding line of CC, where surface gradients and therefore basal shear stresses are very large, $\beta^{2}$ is low. Although the same bed material and roughness, $C_{\mathrm{b}}^{0}$, as well as the same sliding mechanism $(p, q)$ is assumed for the entire model domain, the sliding parameter, $\beta^{2}$, varies spatially over several magnitudes.

The highest modelled surface velocities of the grounded ice can be found close to the grounding lines of the SWIS $\left(\sim 500 \mathrm{~m} \mathrm{a}^{-1}\right)$ and both branches of Veststraumen $\left(\sim 250 \mathrm{~m} \mathrm{a}^{-1}\right)$. Compared with the high jump in velocity at the grounding line of the SWIS, the transition between the grounded and floating parts of Veststraumen is very smooth. Surface velocities at the calving front of the SWIT are slightly less than $1500 \mathrm{~m} \mathrm{a}^{-1}$ and much higher than the surface velocities at the calving front of Veststraumen $\left(\sim 600 \mathrm{~m} \mathrm{a}^{-1}\right)$. The simulated velocities in the RLIS are higher than the observed velocities, especially close to the calving front. The simulated velocities in the BIS area are lower than the observed velocities. The differences between simulated and observed velocities that arise in the scatter plot (Fig. 5) for $u_{\text {obs }} \leq 300 \mathrm{~m} \mathrm{a}^{-1}$ and $300 \mathrm{~m} \mathrm{a}^{-1} \leq u_{\text {sim }} \leq 750 \mathrm{~m} \mathrm{a}^{-1}$ are located mainly in the melange area close to rift 1 between the SWIT and the RLIS and near the calving front of the RLIS. With respect to the statistical quantities and the overall flow pattern, the simulated and observed velocities agree fairly well.

Reference simulation $\operatorname{REF}_{\mathrm{c}}$, where we apply the cold ice rheology everywhere, leads to slightly different results. The mean difference from observed surface velocities decreases to $5.4 \mathrm{ma}^{-1}\left( \pm 71.2 \mathrm{ma}^{-1}\right.$ stddev) for the entire domain, while the absolute mean difference for the grounded part increases. In $R F_{C}$ the simulated surface velocity is still below the observed surface velocity and has a mean difference of $-4.4 \mathrm{ma}^{-1}\left( \pm 19.7 \mathrm{~m} \mathrm{a}^{-1}\right.$ stddev $)$.

\section{Basal sliding including subglacial water}

In this subsection, a set of sensitivity studies investigating the influence of different basal water routing schemes on the modelled ice flow is described. The set-ups are comparable with the reference simulation, but with Budd and Warner $\left(\mathrm{BW}_{\mathrm{t}}\right)$, Quinn $\left(\mathrm{QU}_{\mathrm{t}}\right)$ and Tarboton $\left(\mathrm{TA}_{\mathrm{t}}\right)$ flux routing incorporated in the sliding law $\left(f_{\mathrm{w}} \geq 0\right.$ in Eqn (55)).

Starting from the subglacial water flux and the derived water layer thickness at the end of the spin-up (lower row in Fig. 4), both quantities are recomputed every time-step, as well as the sliding parameter, $\beta^{2}$.

The basal homologous temperatures, basal sliding parameters, $\beta^{2}$, basal sliding velocities and surface velocities for an experiment with $\mathrm{BW}_{\mathrm{t}}$ routing are shown from top to bottom in the right column of Figure 6. Compared with the reference simulation $\left(\mathrm{REF}_{\mathrm{t}}\right)$, shown in Figure 6 (left column), the $\mathrm{BW}_{\mathrm{t}}$ set-up results in lower temperatures in the area of the sticky spot and close to the grounding line at CC. In most areas $\beta^{2}$ is reduced, due to lubrication by subglacial water, but along CC the reduced temperatures lead to larger areas of increased $\beta^{2}$. Especially at CC the areas of enhanced basal motion coincide well with flow features visible on the satellite background image and show individual outlet glaciers in more detail (basal velocities in Fig. 6). Although the TIAF for simulations including subglacial water decreases compared with the reference simulation, the mean velocity increases for the cold and temperate ice rheology. The differences in the surface velocity are not as large as one would expect from the differences in the basal velocity. This is due to a reduction of the deformational part of the velocity in the $\mathrm{BW}_{\mathrm{t}}$ sliding simulation, caused by lower ice temperatures and therefore stiffer ice than for the $\mathrm{REF}_{\mathrm{t}}$ simulation.

The differences between simulated and observed surface velocities for the grounded ice increase for the shown simulations, $\mathrm{REF}_{\mathrm{t}}$ and $\mathrm{BW}_{\mathrm{t}}$, whereas they decrease for the cold ice rheology simulations, $\operatorname{REF}_{\mathrm{c}}$ and $\mathrm{BW}_{\mathrm{c}}$ (Table 3).

To illustrate the temporal evolution of the basal thermal regime, maps of the homologous temperatures are shown at selected time-steps (223-226 ka) for the $\mathrm{BW}_{\mathrm{t}}$ simulation in Figure 7 . The main path of the sticky spot is overlaid as a thick dashed line. At $223 \mathrm{ka}$ the sticky spot is not visible in the temperature field at the observed (low surface velocity in Fig. 2) position in the SWIS, but further upstream of the glacier. In subsequent time-steps this cold area first increases and then moves down to the sticky-spot location (224$225 \mathrm{ka})$. Later the cold area decreases (226-227.5 ka), another cold ice area starts to develop at the same upstream location (227.5-228 ka; not shown) and the cycle begins again. Similar behaviour can be observed for a colder ice area at CC close to the grounding line, while in all other areas the temperature remains mainly unchanged. All simulations including the spin-up, where we use the temperate ice rheo$\operatorname{logy}\left(\mathrm{SU}_{\mathrm{t}}, \mathrm{CON}_{\mathrm{t}}, \mathrm{BW}_{\mathrm{t}}, \mathrm{QU}_{\mathrm{t}}, \mathrm{TA}_{\mathrm{t}}\right)$ show this cyclic behaviour.

We take the TIAF at the base as a proxy for the basal thermal regime and also as a measure of the importance of basal sliding, since sliding is only allowed if the temperature at the base is at pressure-melting point or slightly below (sub-melt sliding). The TIAF, the mean ice velocity (averaged by volume) and the mean basal homologous temperature are shown in Figure 8 for the total time span of $30 \mathrm{ka}$ of the sliding and the control simulations. We discriminate between simulations with temperate $\left(C_{C O N}, R_{t} F_{t}, B W_{t}\right.$, $\left.\mathrm{QU}_{\mathrm{t}}, \mathrm{TA}_{\mathrm{t}}\right)$ and entirely cold $\left(\mathrm{CON}_{\mathrm{C}}, \mathrm{REF}_{\mathrm{C}}, \mathrm{BW}_{\mathrm{C}}, \mathrm{QU}_{\mathrm{c}}, \mathrm{TA}_{\mathrm{C}}\right)$ ice rheology.

Compared with the reference $\left(\mathrm{REF}_{t}\right)$ and the control $\left(\mathrm{CON}_{t}\right)$ simulations, all three sliding simulations under wet 

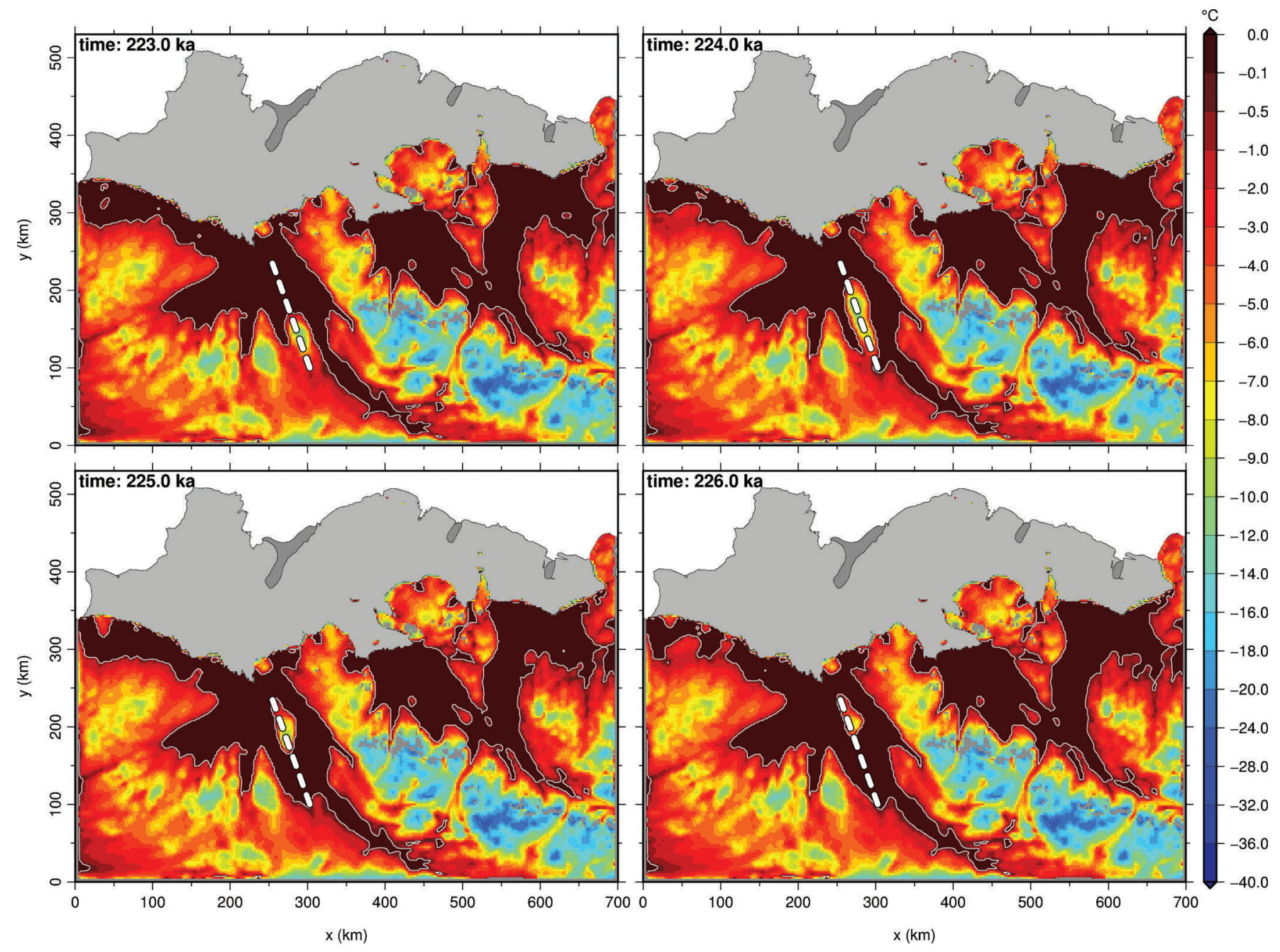

Fig. 7. Maps of the simulated basal homologous temperature of the grounded ice area at the selected time-steps, 223-226 ka, for the BW $\mathrm{t}_{\mathrm{t}}$ simulation. The thick dashed line is the main path of the sticky-spot location over time. The $-0.1^{\circ} \mathrm{C}$ temperature contour is shown in light grey.

basal conditions $\left(\mathrm{BW}_{\mathrm{t}}, \mathrm{QU}_{\mathrm{t}}\right.$ and $\mathrm{TA}_{\mathrm{t}}$ ) have a lower $\mathrm{TIAF}$, indicating a colder ice base. Although the sliding area is reduced, the mean ice velocity increases compared with the reference and control simulations.

All temperate ice rheology simulations show strong temporal variations, due to the internal feedback between flow and temperature fields resulting from the microscopic water content, as already seen in the spin-up experiment. The velocities adjust to the new basal conditions in $<2000$ years, followed by a slight increase over the simulation time. At $222.5 \mathrm{ka}$ the minimal TIAF is reached in the $\mathrm{REF}_{\mathrm{t}}$. At that time, the simulated mean velocity without sliding $\left(\mathrm{CON}_{t}\right)$ is higher than the velocity with sliding $\left(\mathrm{REF}_{\mathrm{t}}\right)$. Up to $213 \mathrm{ka}$ the mean velocity and the TIAF of all experiments are nearly in phase, but have different amplitudes. After that $\mathrm{BW}_{\mathrm{t}}, \mathrm{QU}_{\mathrm{t}}$ and $\mathrm{TA}_{\mathrm{t}}$ are running out of phase, while $\mathrm{REF}_{\mathrm{t}}$ and $\mathrm{CON}_{\mathrm{t}}$ are slightly in phase for another $\sim 7$ ka before they diverge. Simulations with basal water exhibit larger temporal variability than the $\operatorname{REF}_{t}$ and $\mathrm{CON}_{t}$ experiments. At least for the first half of the sliding simulations, the mean velocity of the reference and control simulations shows a saw-tooth-like waveform with a repetition frequency of $\sim 5000 \mathrm{a}^{-1}$ that is modified by another frequency close to $\sim 2000 \mathrm{a}^{-1}$. For all sliding simulations, the occurrence of the maxima in TIAF corresponds well with maxima in the mean velocity. In the non-sliding control simulation the maxima in the mean velocity occur after the maxima of the TIAF ( 300-500 years, e.g. at 214, 218 and $222 \mathrm{ka}$ ). The three flux-routing schemes work similarly up to $\sim 226 \mathrm{ka}$, when they start to diverge. Simulations performed with a cold ice rheology (thinner curves in Fig. 8) result in higher TIAFs but lower mean ice velocities, and show much smaller temporal variations. Although the temporal variations for all quantities shown in the figure are small in the cold ice rheology simulations, they increase considerably for simulations that include basal water in the sliding relation. Simulations with cold and temperate ice rheology show the same general picture: more basal sliding results in higher mean velocities, but smaller TIAF.

\section{Sticky-spot area}

In the observed surface velocity field (Fig. 2), as well as in the simulations performed in this study, a relatively slowmoving part in the SWIS has been identified at $x \approx 270 \mathrm{~km}$ and $y \approx 200 \mathrm{~km}$. This area shows a large temporal variability in all temperate ice rheology simulations, including the spinup experiment. In Figure 9 the surface velocity, the basal velocity, the basal friction heat, the basal strain heat, the thickness of the basal temperate ice layer and the basal homologous temperature are shown for $\mathrm{CON}_{t}, \mathrm{REF}_{t}$ and $\mathrm{BW}_{\mathrm{t}}$. For a later comparison $\mathrm{CON}_{\mathrm{C}}$ is also shown. 


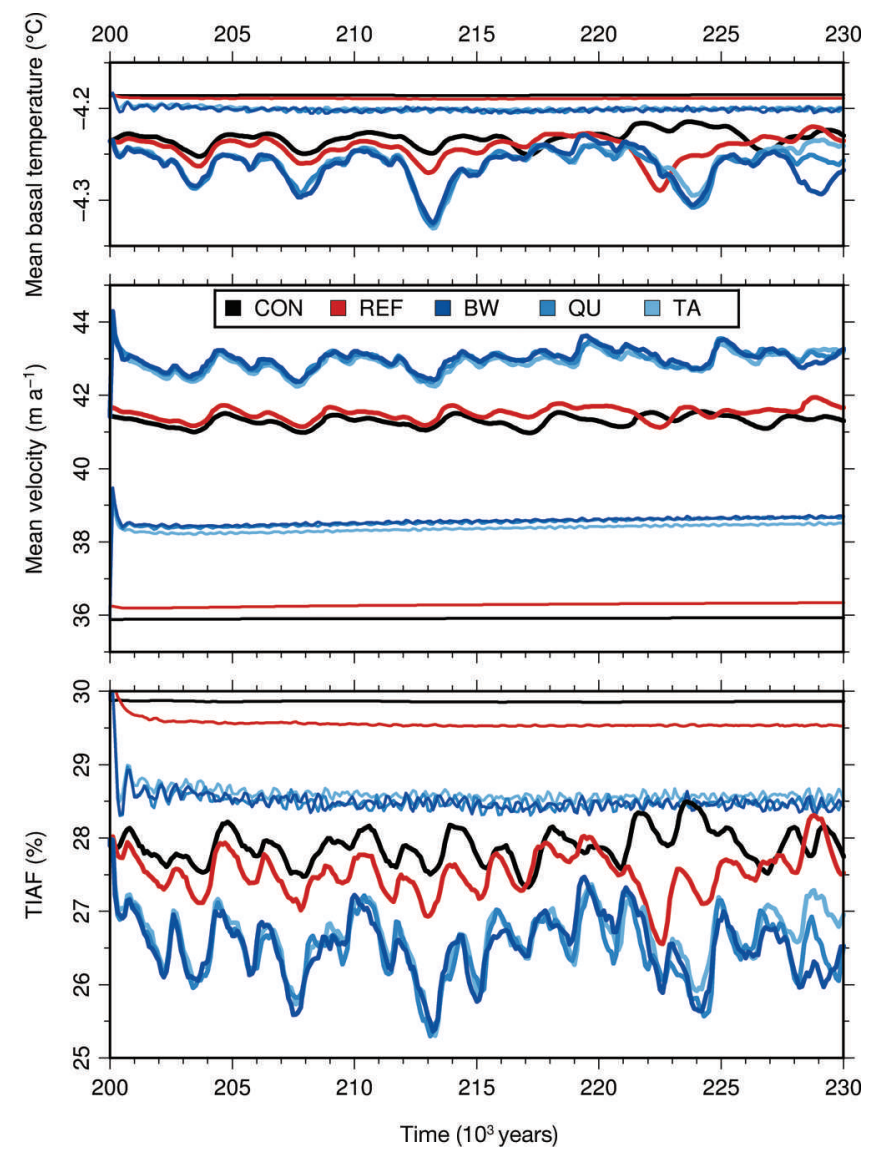

Fig. 8. Temporal evolution of the mean basal homologous temperature of the grounded ice, the mean over all ice velocities and the temperate ice area fraction (TIAF) at the base (top to bottom) during the $30 \mathrm{ka}$ for the control $\left(\mathrm{CON}_{\mathrm{t}}\right.$, black), reference $\left(R E F_{t}\right.$, red) and sliding simulations (dark to light blue) for the different flux-routing methods $\left(\mathrm{BW}_{\mathrm{t}}, \mathrm{QU}_{\mathrm{t}}, \mathrm{TA}_{\mathrm{t}}\right)$. Simulations performed with the cold ice rheology $\left(\mathrm{CON}_{\mathrm{c}}, \mathrm{REF}_{\mathrm{C}}, \mathrm{BW}_{\mathrm{c}}, \mathrm{QU}_{\mathrm{C}}\right.$ $\mathrm{TA}_{\mathrm{c}}$ ) are represented by thinner curves for comparison.

In the figure, two main classes of simulation need to be distinguished: (1) experiments where basal sliding is suppressed $\left(\mathrm{CON}_{\mathrm{t}}\right.$ and $\left.\mathrm{CON}_{\mathrm{C}}\right)$ and (2) simulations where basal sliding is allowed $\left(\mathrm{REF}_{\mathrm{t}}\right.$ and $\left.\mathrm{BW}_{\mathrm{t}}\right)$. Since all sliding experiments that include basal water routing have very similar behaviour, only the $\mathrm{BW}_{\mathrm{t}}$ simulation is shown in the figure, as a representative. The simulation with cold ice rheology $\left(\mathrm{CON}_{\mathrm{c}}\right)$ shows no temporal variations in any quantity (e.g. a constant surface velocity of $19 \mathrm{~m} \mathrm{a}^{-1}$ ), meaning that the ice is already in steady state after $S U_{c}$. All other simulations in Figure 9 show strong temporal variations. The temporal behaviour is similar for at least $15 \mathrm{ka}$ after the spin-up, before the simulations start to deviate considerably. As shown above (Fig. 8), the minimum basal temperature decreases with increasing basal sliding $\left(\mathrm{CON}_{\mathrm{t}}:-7.3^{\circ} \mathrm{C}\right.$; $\mathrm{REF}_{\mathrm{t}}$ : $-7.8^{\circ} \mathrm{C}$; $\mathrm{BW}_{\mathrm{t}}$ : $-8.1^{\circ} \mathrm{C}$ ). The periods of temperature cycles are slightly less than $5 \mathrm{ka}$ and much longer than the periods identified for the domain average values (Fig. 8). The minima in the basal temperature are missing for the $\mathrm{REF}_{\mathrm{t}}$ and $\mathrm{CON}_{\mathrm{t}}$ simulations, if a temperate basal ice layer is available. Both simulations show a maximum thickness of temperate ice of $H_{\text {temp }}=9.6 \mathrm{~m}$, which is the thickness of the lowermost ice layer at this position. The missing minima in the strain-heating term are also correlated with the occurrence of temperate ice at the base. The range of strain heating over time is between $\sim 10^{-4}$

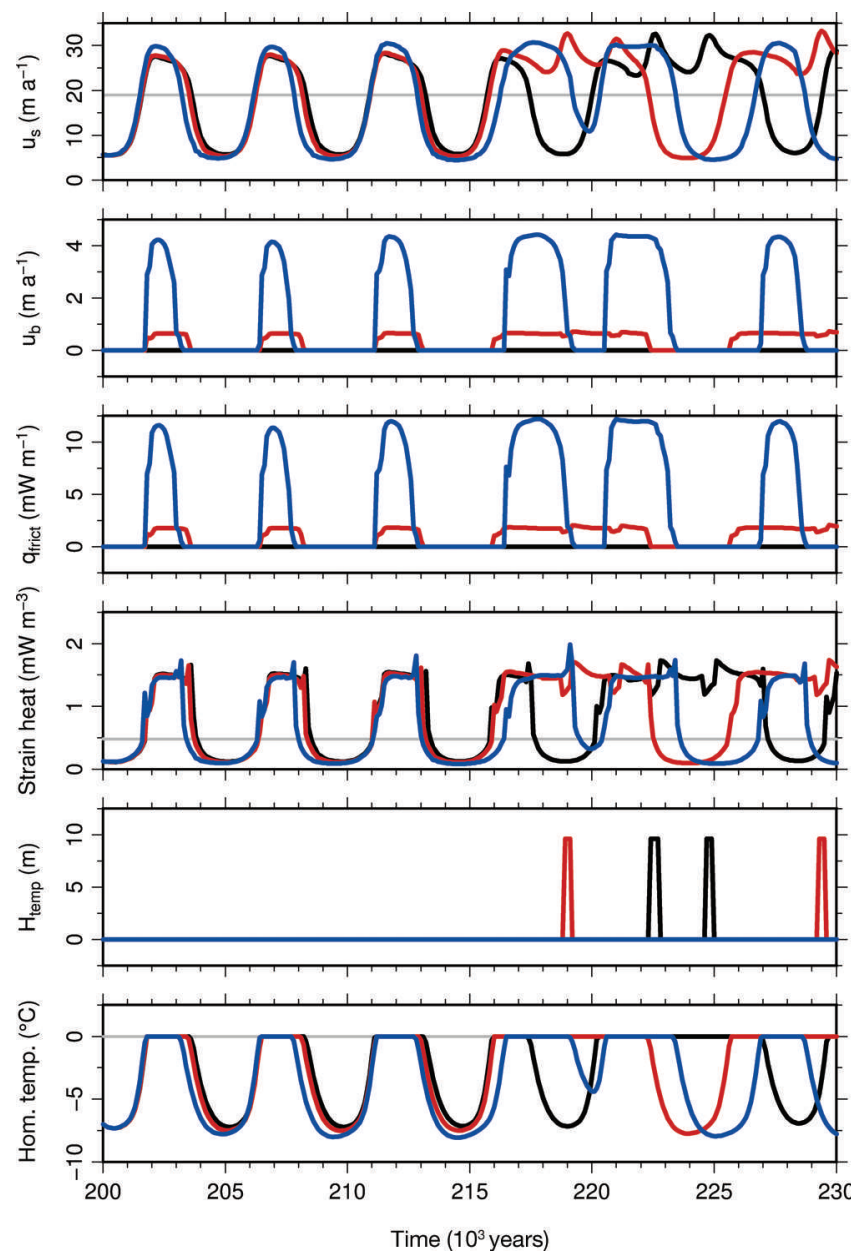

Fig. 9. Temporal evolution of the ice at the sticky-spot location for the control $\left(\mathrm{CON}_{\mathrm{t}}\right.$, black), the reference $\left(\mathrm{REF}_{\mathrm{t}}\right.$, red) and the sliding experiment including Budd and Warner routing (BW, blue). The surface velocity, $u_{\mathrm{s}}$, the basal velocity, $u_{\mathrm{b}}$, the basal friction heating, $q_{\text {frict }}$, the strain heat of the lowermost gridpoint, the thickness of the basal temperate layer, $H_{\text {temp, }}$ and the basal homologous temperature are shown from top to bottom. For comparison, the values of the cold ice rheology simulation without basal sliding $\left(\mathrm{CON}_{\mathrm{C}}\right)$ are shown in grey.

and $1.5 \times 10^{-3} \mathrm{~W} \mathrm{~m}^{-3}$. The temporal means $\left(\mathrm{CON}_{\mathrm{t}}\right.$ : 0.8 ; $\mathrm{REF}_{\mathrm{t}}: 0.9 ; \mathrm{BW}_{\mathrm{t}}: 0.7 \times 10^{-3} \mathrm{~W} \mathrm{~m}^{-3}$ ) are clearly above the $0.5 \times 10^{-3} \mathrm{~W} \mathrm{~m}^{-3}$ value for the cold ice simulation, $\mathrm{CON}_{\mathrm{c}}$. The heat supplied by basal friction is small, with temporal means of $1 \times 10^{-3} \mathrm{~W} \mathrm{~m}^{-2}\left(\mathrm{REF}_{\mathrm{t}}\right)$ and $4 \times 10^{-3} \mathrm{~W} \mathrm{~m}^{-2}\left(\mathrm{BW}_{\mathrm{t}}\right)$ compared with $53 \times 10^{-3} \mathrm{~W} \mathrm{~m}^{-2}$ supplied by the geothermal heat flux. The sliding velocity is very low at this position $\left(R_{\mathrm{t}}: 0.7 \mathrm{~m} \mathrm{a}^{-1}\right.$, maximum) even for the enhanced sliding simulation $\left(\mathrm{BW}_{\mathrm{t}}\right.$ : $4.4 \mathrm{~m} \mathrm{a}^{-1}$, maximum). Highest surface velocities are reached in peaks in the $\mathrm{REF}_{\mathrm{t}}$ simulation, where the velocity matches the observation of $33 \mathrm{~m} \mathrm{a}^{-1}$. In the more general view, the surface velocities in the $\mathrm{BW}_{\mathrm{t}}$ simulation show higher local maxima, with magnitudes of $\sim 30 \mathrm{~m} \mathrm{a}^{-1}$, which are in the range of $10 \%$ of the observations. During time intervals with a cold ice base, the simulated surface velocities are much smaller than observed.

\section{DISCUSSION}

We run the model into thermal steady state based on the present-day climate (surface temperatures). This 
overestimates the mean ice temperature and therefore the contribution of ice deformation to the surface velocity. However, it is only possible to study the impact of subglacial water and microscopic water inclusions when perturbation experiments are started from a model in a steady state, so the results are not overlain by the model transient behaviour.

Due to the multilayer approach of the full-Stokes model we were able to run the simulations over long timescales. At the end of the thermocoupled spin-up simulation, performed over $200 \mathrm{ka}$ without basal sliding, the simulated surface velocities already agree well with the observed velocities. We therefore conclude that the occurrence of ice streams in the model domain is mainly controlled by the geometry (Winsborrow and others, 2010).

The basal sliding parameter, $C_{\mathrm{b}}^{0}$, used in subsequent simulations over another $30 \mathrm{ka}$ is relatively low, taking into account the already high contribution of deformation to the total velocity. We do not state that our choice of sliding parameters $(p, q, \nu)$ is the only way to match the observations. However, the aim of this study is to analyse the effect of subglacial water as an additional contributor to the sliding, and hypothesize a similar effect for other parameter choices.

Including the basal water in the sliding relation increases the mean velocity of the ice and therefore ice transport over the grounding line, compared with the reference simulations. The three different flux-routing methods lead to similar results, most likely because the main water flux points along the grid orientation in the $y$-direction. In this case the differences between the different schemes are smallest (Fig. 4; Le Brocq and others, 2009).

The mean differences between all sliding simulations and the observed velocity field are $<5 \mathrm{~m} \mathrm{a}^{-1}$ for the grounded ice, with a high correlation, $\sim 0.8$. The best fit to the observations is given by the Budd and Warner routing in combination with a cold ice rheology, but we hypothesize that other combinations of model parameters in the sliding law or a lower value of the microscopic water content would lead to slightly different results.

Simulations with basal water do not show increased sliding at all locations compared with the reference simulations. Some areas at CC show a slight decrease in the surface velocity because of the changes in the basal thermal regime. This corresponds well with pronounced glacier flow in that area. The simulations show that sliding, especially the enhanced sliding due to basal water, leads to a reduction of the TIAF and the mean basal temperature (Fig. 8). Since both quantities are taken as domain averages, temporal changes in small areas or just spatial differences between different time slices are not resolved well, but are clearly visible between different time-steps (Fig. 7). Although the area of sliding decreases and the viscosity of the ice at the base increases due to lower temperatures, the mean ice velocity increases with increased sliding. We conclude that enhanced flow occurs in smaller areas. The enhanced flow is also visible in the distribution of the basal velocities in Figure 6.

Our simulations also show decreasing basal temperatures with increasing basal sliding. The effect is largest if we use enhanced sliding due to basal water (lower basal temperatures and TIAFs in Fig. 8). In a two-dimensional (2-D) flowline model, Pattyn (1996) argued that an increase in basal velocity caused an increase in vertical advection rates transporting colder ice downward to the base, decreasing the area subjected to basal melting (TIAF), decreasing the total area of lubrication and therefore also decreasing the area of enhanced sliding and the velocity itself. It was found that whenever basal velocity plays a major role, its effect on the ice-sheet dynamics is largely controlled by the ice-sheet temperature. It was further noted that the disintegration of an ice sheet is partly counteracted by colder basal temperatures due to enhanced sliding. In contrast to the findings of Pattyn (1996) the overall mean velocity increases if we allow for sliding.

In our 3-D simulations the flow is more concentrated in smaller areas (the flow pattern changes horizontally), which was not possible in Pattyn's 2-D flowline model. The simulations $\mathrm{BW}_{\mathrm{C}}, \mathrm{QU}_{\mathrm{c}}$ and $\mathrm{TA}_{\mathrm{c}}$ are very similar to the type 1 sliding relation used by Pattyn (1996), but show only minor temporal variations that are not comparable with the cyclic behaviour found by Pattyn, because we use a fixed geometry. If we account for basal water in the sliding, the sliding velocities increase and therefore the advection of colder ice to the base increases, explaining the larger temporal variations of the TIAF, the mean basal temperature and the mean velocity in the $\mathrm{BW}_{\mathrm{C}}, \mathrm{QU}_{\mathrm{c}}$ and $\mathrm{TA}_{\mathrm{c}}$ simulations, compared with the $\mathrm{REF}_{\mathrm{C}}$ simulation.

Van Pelt and Oerlemans (2012) recently described a basal water feedback based on the assumption that higher sliding velocities induce more heat production by frictional heating and consequently more basal meltwater lubricating the bed. Our results do not show this feedback. This is probably due to lower sliding velocities in our simulations which do not produce enough friction heat at the base to change the temperature regime significantly, and due to the missing feedback between the flow and geometry evolution of the ice in our model.

Although we run our model with constant forcing and a fixed geometry, all simulations performed with a temperate ice rheology do not run into steady state, independent of whether we allow for basal sliding or not (e.g. $C \mathrm{~N}_{\mathrm{t}}, \mathrm{REF}_{\mathrm{t}}$ $\mathrm{BW}_{t}, \mathrm{QU}_{\mathrm{t}}$ and $\mathrm{TA}_{\mathrm{t}}$ in Fig. 8). The domain-averaged variations of the TIAF, the velocity and the basal temperature in this figure appear small, but the temperate ice rheology simulations lead to significant temporal variations at several areas in the model domain, such as the sticky spot, where the surface velocity varies by a factor of 5 over the $30 \mathrm{ka}$ simulation time (Fig. 9).

As suggested by Robin (1955) and discussed in more detail by Clarke and others (1977), the ice is subjected to creep instability, based on nonlinear coupling between the temperature and the flow of ice via the creep relation (Eqn (12)). The parameter values of Paterson and Budd (1982) used in the rate factor (Eqn (13)) vary by three orders of magnitude over the temperature range found in the ice. Thus a small increase in deformation rate, by increasing the strain heating and therefore the temperature in the ice, will result in a further increase in deformation rate.

Payne and Dongelmans (1997) applied a 3-D, thermomechanical ice-sheet model to an idealized ice-sheet geometry. The work they reported showed that localized creep instabilities can be responsible for the onset of streaming, based only on internal feedbacks within the ice. We infer that creep instability is responsible for the temporal variations of the ice flow in our model. If a creep instability occurs locally, the resulting enhanced flow at the base causes increasing horizontal and vertical advection rates. In particular, the vertical advection of cold ice to the base will decrease the temperature in the basal ice layers and therefore the ice deformation. The whole process gives rise to a cyclic 
behaviour (cf. non-sliding simulation $\mathrm{CON}_{\mathrm{t}}$ ). The process is further amplified if we also take basal sliding into account. This can be seen in Figure 8, where the simulations with the highest sliding velocities $\left(\mathrm{BW}_{\mathrm{t}}, \mathrm{QU}_{\mathrm{t}}\right.$ and $\left.\mathrm{TA}_{\mathrm{t}}\right)$ also show the largest temporal variability for the TIAF, the mean velocity and mean basal temperature. Due to sliding at the base, shearing in the basal ice layers becomes less effective, thus reducing the amount of strain heating in these layers, and, in addition, more cold ice is advected from the surface to the base. The reduction of strain heating at the base caused by sliding cannot be compensated by the additional friction heat and prevents the development of a temperate ice layer at the sticky-spot location, at least for the simulated time period in the $\mathrm{BW}_{\mathrm{t}}$ simulation (Fig. 9). This is in good agreement with the findings of Blatter and Hutter (1991), who concluded that strain heating is the necessary mechanism to produce a temperate ice layer at the base. The parameterization of the temperate ice rheology with a constant water content if the ice reaches the pressure-melting point supports the occurrence of a creep instability, since ice at the pressure-melting point becomes even softer and enhances the positive feedback of the creep instability. In particular for the relative high water content of $1 \%$ (upper limit for which Eqn (14) holds true) the softening effect is largest. For future studies our model would therefore benefit from an explicit solution of the enthalpy and subsequently temperature and the water content, as in Aschwanden and others (2012).

\section{CONCLUSIONS}

Motivated by the importance of water for the rheology of temperate ice (microscopic water content) and for the basal lubrication (macroscopic water sheet), we examined their long-timescale effects using the 3-D, thermocoupled, fullStokes ice-flow model TIM-FD ${ }^{3}$ on a $2.5 \mathrm{~km}$ horizontal grid, for an area covering major ice streams in western Dronning Maud Land adjacent to the Brunt and Riiser-Larsen Ice Shelves. We implemented three different flux-routing algorithms for the subglacial meltwater and modified a Weertman-type sliding relation to account for higher sliding velocities under wet basal conditions. Subsequent to fullStokes spin-up simulations over $200 \mathrm{ka}$, different sliding simulations, each covering a model time span of $30 \mathrm{ka}$, were performed. We find the occurrence of the major ice streams in the study area to be mainly controlled by the ice and bedrock geometry. Smaller glaciers draining into the Brunt Ice Shelf only appear as pronounced individual glaciers when lubrication coupled to subglacial water layer thickness is taken into account. We observed in the simulations that sliding with subglacial water routing leads to increased velocities, although the effective sliding area decreases because of the temperature change at the base. Simulations performed with a temperate ice rheology result in cyclic behaviour of the ice flow on millennial timescales at distinct locations in the model domain, which is even stronger if the water layer thickness is considered in the sliding law. Further investigations of the cyclic behaviour are planned for the future and require the solution of the enthalpy evolution to improve model estimates of the water content in the ice.

\section{ACKNOWLEDGEMENTS}

We thank M. Rückamp and F. Ziemen who read drafts of the text and contributed useful ideas and discussions.

\section{REFERENCES}

Aris R (1989) Vectors, tensors and basic equations of fluid mechanics. Prentice-Hall, Englewood Cliffs, NJ

Aschwanden A, Bueler E, Khroulev C and Blatter H (2012) An enthalpy formulation for glaciers and ice sheets. J. Glaciol., 58(209), 441-457 (doi: 10.3189/2012JoG11J088)

Blatter $\mathrm{H}$ and Hutter K (1991) Polythermal conditions in Arctic glaciers. J. Glaciol., 37(126), 261-269

Budd WF and Jenssen D (1987) Numerical modelling of the largescale basal water flux under the West Antarctic ice sheet. In Van der Veen CJ and Oerlemans J eds. Dynamics of the West Antarctic ice sheet. D Reidel, Dordrecht, 293-320

Budd WF and Warner RC (1996) A computer scheme for rapid calculations of balance-flux distributions. Ann. Glaciol., 23, 21-27

Carter SP and Fricker HA (2012) The supply of subglacial meltwater to the grounding line of the Siple Coast, West Antarctica. Ann. Glaciol., 53(60 Pt 2), 267-280 (doi: 10.3189/2012AoG60A119)

Clarke GKC, Nitsan U and Paterson WSB (1977) Strain heating and creep instability in glaciers and ice sheets. Rev. Geophys. Space Phys., 15(2), 235-247 (doi: 10.1029/RG015i002p00235)

Comiso JC (2000) Variability and trends in Antarctic surface temperatures from in situ and satellite infrared measurements. J. Climate, 13(10), 1674-1696 (doi: 10.1175/15200442(2000)013<1674:VATIAS>2.0.CO;2)

Durand G, Gagliardini O, Zwinger T, Le Meur E and Hindmarsh RCA (2009) Full Stokes modeling of marine ice sheets: influence of the grid size. Ann. Glaciol., 50(52), 109-114 (doi: 10.3189/ 172756409789624283)

Duval P (1977) The role of the water content on the creep rate of polycrystalline ice. IAHS Publ. 118 (Symposium at Grenoble 1975 - Isotopes and Impurities in Snow and Ice), 29-33

Ferziger JH and Perić M (2002) Computational methods for fluid dynamics. Springer, Berlin

Fricker HA and Scambos T (2009) Connected subglacial lake activity on lower Mercer and Whillans Ice Streams, West Antarctica, 2003-2008. J. Glaciol., 55(190), 303-315 (doi: 10.3189/002214309788608813)

Fricker HA, Scambos T, Bindschadler R and Padman L (2007) An active subglacial water system in West Antarctica mapped from space. Science, 315(5818), 1544-1548 (doi: 10.1126/science. 1136897)

Gladstone RM, Lee V, Vieli A and Payne AJ (2010) Grounding line migration in an adaptive mesh ice sheet model. J. Geophys. Res., 115(F4), F04014 (doi: 10.1029/2009JF001615)

Glen JW (1955) The creep of polycrystalline ice. Proc. R. Soc. London, Ser. A, 228(1175), 519-538 (doi: 10.1098/rspa. 1955.0066)

Greve R (2005) Relation of measured basal temperatures and the spatial distribution of the geothermal heat flux for the Greenland ice sheet. Ann. Glaciol., 42(1), 424-432 (doi: 10.3189/ 172756405781812510)

Greve R and Blatter H (2009) Dynamics of ice sheets and glaciers. Springer, Dordrecht

Haran T, Bohlander J, Scambos T and Fahnestock M (2005) MODIS mosaic of Antarctica (MOA) image map. National Snow and Ice Center, Boulder, CO. Digital media: http://nsidc.org/data/nsidc0280.html

Hindmarsh RCA (2004) A numerical comparison of approximations to the Stokes equations used in ice sheet and glacier modeling. J. Geophys. Res., 109(F1), F01012 (doi: 10.1029/2003JF000065)

Hindmarsh RCA and Le Meur E (2001) Dynamical processes involved in the retreat of marine ice sheets. J. Glaciol., 47(157), 271-282 (doi: 10.3189/172756501781832269)

Holland DM and Jenkins A (1999) Modeling thermodynamic iceocean interactions at the base of an ice shelf. J. Phys. Oceanogr., 29(8), 1787-1800 (doi: 10.1175/1520-0485(1999)029<1787: MTIOIA $>2.0 . \mathrm{CO} ; 2)$

Hulbe CL, Johnston R, Joughin I and Scambos T (2005) Marine ice modification of fringing ice shelf flow. Arct. Antarct. Alp. Res., 
37(3), 323-330 (doi: 10.1657/1523-0430(2005)037[0323: MIMOFI]2.0.CO;2)

Humbert A (2010) The temperature regime of Fimbulisen, Antarctica. Ann. Glaciol., 51(55), 56-64 (doi: 10.3189/ 172756410791392673)

Humbert A, Kleiner T, Mohrholz C-O, Oelke C, Greve R and Lange MA (2009) A comparative modeling study of the Brunt Ice Shelf/ Stancomb-Wills Ice Tongue system, East Antarctica. J. Glaciol., 55(189), 53-65 (doi: 10.3189/002214309788608949)

Johnson J and Fastook J (2002) Northern Hemisphere glaciation and its sensitivity to basal melt water. Quat. Int., 95-6, 65-74 (doi: 10.1016/S1040-6182(02)00028-9)

Khazendar A, Rignot E and Larour E (2009) Roles of marine ice, rheology, and fracture in the flow and stability of the Brunt/ Stancomb-Wills Ice Shelf. J. Geophys. Res., 114(F4), F04007 (doi: 10.1029/2008JF001124)

Kleiner T (2010) Entwicklung eines dreidimensionalen numerischen full-Stokes-Fließmodells und seine Anwendung Inlandeis-Schelfssystem der Antarktis im Bereich des westlichen Dronning Maud Land. (Dr. rer. nat. dissertation, University of Münster)

Le Brocq AM, Payne AJ and Siegert MJ (2006) West Antarctic balance calculations: impact of flux-routing algorithm, smoothing algorithm and topography. Comput. Geosci., 32(10), 1780-1795 (doi: 10.1016/j.cageo.2006.05.003)

Le Brocq AM, Payne AJ, Siegert MJ and Alley RB (2009) A subglacial water-flow model for West Antarctica. J. Glaciol., 55(193), 879-888 (doi: 10.3189/002214309790152564)

Le Brocq AM, Payne AJ and Vieli A (2010) An improved Antarctic dataset for high resolution numerical ice sheet models (ALBMAP v1). Earth Syst. Sci. Data, 2(2), 247-260 (doi: 10.5194/essdd-3195-2010)

Lliboutry L and Duval P (1985) Various isotropic and anisotropic ices found in glaciers and polar ice caps and their corresponding rheologies. Ann. Geophys., 3(2), 207-224

Lythe MB, Vaughan DG and BEDMAP consortium (2001) BEDMAP: a new ice thickness and subglacial topographic model of Antarctica. J. Geophys. Res., 106(B6), 11335-11351 (doi: 10.1029/2000JB900449)

MacAyeal DR, Bindschadler RA and Scambos TA (1995) Basal friction of Ice Stream E, West Antarctica. J. Glaciol., 41(138), 247-262

MacAyeal DR, Rommelaere V, Huybrechts P, Hulbe CL, Determann $J$ and Ritz C (1996) An ice-shelf model test based on the Ross Ice Shelf, Antarctica. Ann. Glaciol., 23, 46-51

Neckel N, Drews R, Rack W and Steinhage D (2012) Basal melting at the Ekström Ice Shelf, Antarctica, estimated from mass flux divergence. Ann. Glaciol., 53(60 Pt 2), 294-302 (doi: 10.3189/ 2012AoG60A167)

Nye JF (1957) The distribution of stress and velocity in glaciers and ice-sheets. Proc. R. Soc. London, Ser. A, 239(1216), 113-133 (doi: 10.1098/rspa.1957.0026)

Paterson WSB (1994) The physics of glaciers, 3rd edn. Elsevier, Oxford

Paterson WSB and Budd WF (1982) Flow parameters for ice sheet modeling. Cold Reg. Sci. Technol., 6(2), 175-177 (doi: 10.1016/ 0165-232X(82)90010-6)

Pattyn F (1996) Numerical modelling of a fast-flowing outlet glacier: experiments with different basal conditions. Ann. Glaciol., 23, 237-246

Pattyn F (2002) Transient glacier response with a higher-order numerical ice-flow model. J. Glaciol., 48(162), 467-477 (doi: 10.3189/172756502781831278)

Pattyn F (2003) A new three-dimensional higher-order thermomechanical ice-sheet model: basic sensitivity, ice stream development, and ice flow across subglacial lakes. J. Geophys. Res., 108(B8), 2382 (doi: 10.1029/2002JB002329)

Pattyn F (2010) Antarctic subglacial conditions inferred from a hybrid ice sheet-ice stream model. Earth Planet. Sci. Lett., 295(3-4), 451-461 (doi: 10.1016/j.epsl.2010.04.025)
Pattyn F, de Brabander S and Huyghe A (2005) Basal and thermal control mechanisms of the Ragnhild glaciers, East Antarctica. Ann. Glaciol., 40, 225-231 (doi: 10.3189/ 172756405781813672)

Pattyn F and 20 others (2008) Benchmark experiments for higher-order and full-Stokes ice sheet models (ISMIPHOM). Cryosphere, 2(2), 95-108 (doi: 10.5194/tc-295-2008)

Pattyn F and 18 others (2012) Results of the Marine Ice Sheet Model Intercomparison Project, MISMIP. Cryosphere, 6(3), 573-588 (doi: 10.5194/tc-6-573-2012)

Pattyn F and 27 others (2013) Grounding-line migration in planview marine ice-sheet models: results of the ice2sea MISMIP3d intercomparison. J. Glaciol., 59(215), 410-422 (doi: 10.3189/ 2013JoG12J129)

Pavlis NK, Holmes SA, Kenyon SC and Factor JK (2008) An Earth gravitational model to degree 2160: EGM2008. Geophys. Res. Abstr., 10, EGU2008-A-01891

Payne AJ (1995) Limit cycles in the basal thermal regime of ice sheets. J. Geophys. Res., 100(B3), 4249-4263 (doi: 10.1029/ 94JB02778)

Payne AJ and Dongelmans PW (1997) Self-organization in the thermomechanical flow of ice sheets. J. Geophys. Res., 102(B6), 12 219-12 233 (doi: 10.1029/97JB00513)

Pimentel S, Flowers GE and Schoof CG (2010) A hydrologically coupled higher-order flow-band model of ice dynamics with a Coulomb friction sliding law. J. Geophys. Res., 115(F4), F04023 (doi: 10.1029/2009JF001621)

Press WH, Teukolsky SA, Vetterling WT and Flannery BP (1992) Numerical recipes in FORTRAN: the art of scientific computing, 2nd edn. Cambridge University Press, Cambridge

Quinn P, Beven K, Chevallier P and Planchon O (1991) The prediction of hillslope flow paths for distributed hydrological modeling using digital terrain models. Hydrol. Process., 5(1), 59-79 (doi: 10.1002/hyp.3360050106)

Rignot E, Mouginot J and Scheuchl B (2011) Ice flow of the Antarctic Ice Sheet. Science, 333(6048), 1427-1430 (doi: 10.1126/science.1208336)

Robin GdeQ (1955) Ice movement and temperature distribution in glaciers and ice sheets. J. Glaciol., 2(18), 523-532 (doi: 10.3189/002214355793702028)

Saad Y (2003) Iterative methods for sparse linear systems. Society for Industrial and Applied Mechanics, Philadelphia, PA

Sato T and Greve R (2012) Sensitivity experiments for the Antarctic ice sheet with varied sub-ice-shelf melting rates. Ann. Glaciol., 53(60 Pt 2), 221-228 (doi: 10.3189/2012AoG60A042)

Schodlok M, Menemenlis D, Rignot E and Studinger M (2012) Sensitivity of the ice-shelf/ocean system to the sub-ice-shelf cavity shape measured by NASA IceBridge in Pine Island Glacier, West Antarctica. Ann. Glaciol., 53(60 Pt 2), 156-162 (doi: 10.3189/2012AoG60A073)

Shapiro NM and Ritzwoller MH (2004) Inferring surface heat flux distribution guided by a global seismic model: particular application to Antarctica. Earth Planet. Sci. Lett., 223(1-2), 213-224 (doi: 10.1016/j.epsl.2004.04.011)

Shreve RL (1972) Movement of water in glaciers. J. Glaciol., 11(62), 205-214

Siegert MJ (2000) Antarctic subglacial lakes. Earth-Sci. Rev., 50(1-2), 29-50 (doi: 10.1016/S0012-8252(99)00068-9)

Siegert MJ, Carter S, Tabacco I, Popov S and Blankenship DD (2005) A revised inventory of Antarctic subglacial lakes. Antarct. Sci., 17(3), 453-460 (doi: 10.1017/S0954102005002889)

Smith BE, Fricker HA, Joughin IR and Tulaczyk S (2009) An inventory of active subglacial lakes in Antarctica detected by ICESat (2003-2008). J. Glaciol., 55(192), 573-595 (doi: $10.3189 / 002214309789470879)$

Spalding DB (1972) A novel finite difference formulation for differential expressions involving both first and second derivatives. Int. J. Num. Meth. Eng., 4(4), 551-559 (doi: 10.1002/ nme.1620040409) 
Stearns LA, Smith BE and Hamilton GS (2008) Increased flow speed on a large East Antarctic outlet glacier caused by subglacial floods. Nature Geosci., 1(12), 827-831 (doi: 10.1038/ngeo356)

Steinemann S (1954) Results of preliminary experiments on the plasticity of ice crystals. J. Glaciol., 2(16), 404-413 (doi: 10.3189/002214354793702533)

Steinemann S (1958) Résultats expérimentaux sur la dynamique de la glace et leurs corrélations avec le mouvement et la pétrographie des glaciers. IASH Publ. 47 (Symposium at Chamonix 1958 - Physics of the Movement of the Ice), 184-198

Steinhage D, Nixdorf U, Meyer U and Miller H (2001) Subglacial topography and internal structure of central, western Dronning Maud Land, Antarctica, determined from airborne radio echo sounding. J. Appl. Geophys., 47(3-4), 183-189 (doi: 10.1016/ S0926-9851(01)00063-5)

Tarboton DG (1997) A new method for the determination of flow directions and upslope areas in grid digital elevation models. Water Resour. Res., 33(2), 309-319 (doi: 10.1029/96WR03137)

Thoma M, Grosfeld K and Lange MA (2006) Impact of the Eastern Weddell Ice Shelves on water masses in the eastern Weddell Sea. J. Geophys. Res., 111(C12), C12010 (doi: 10.1029/ 2005JC003212)

Timmermann R, Wang Q and Hellmer HH (2012) Ice-shelf basal melting in a global finite-element sea-ice/ice-shelf/ocean model. Ann. Glaciol., 53(60 Pt 2), 303-314 (doi: 10.3189/ 2012AoG60A156)

Van de Berg WJ, Van den Broeke MR, Reijmer $\mathrm{CH}$ and Van Meijgaard E (2006) Reassessment of the Antarctic surface mass balance using calibrated output of a regional atmospheric climate model. J. Geophys. Res., 111(D11), D11104 (doi: 10.1029/2005JD006495)
Van der Veen CJ and Whillans IM (1989a) Force budget: I. Theory and numerical methods. J. Glaciol., 35(19), 53-60

Van der Veen CJ and Whillans IM (1989b) Force budget: II. Application to two-dimensional flow along Byrd station strain network, Antarctica. J. Glaciol., 35(119), 61-67

Van Pelt, WJJ and Oerlemans J (2012) Numerical simulations of cyclic behaviour in the Parallel Ice Sheet Model (PISM). J. Glaciol., 58(208), 347-360

Weertman J (1957) Deformation of floating ice shelves. J. Glaciol., 3(21), 287-303

Weertman J (1964) The theory of glacier sliding. J. Glaciol., 5(39), 287-303

Weertman J (1966) Effect of a basal water layer on the dimensions of ice sheets. J. Glaciol., 6(44), 191-207

Weertman J (1969) Water lubrication mechanism of glacier surges. Can. J. Earth Sci., 6(4), 929-942

Weertman J (1972) General theory of water flow at the base of a glacier or ice sheet. Rev. Geophys., 10(1), 287-333

Weertman J and Birchfield GE (1982) Subglacial water flow under ice streams and West Antarctic ice-sheet stability. Ann. Glaciol., 3, 316-320

Weis M, Greve R and Hutter K (1999) Theory of shallow ice shelves. Cont. Mech. Thermodyn., 11, 11-50

Whillans IM (1987) Force budget of ice sheets. Kluwer Academic, Dordrecht, $17-36$

Winsborrow MCM, Clark CD and Stokes CR (2010) What controls the location of ice streams? Earth-Sci. Rev., 103(3-4), $45-59$

Zwally HJ and 7 others (2005) Mass changes of the Greenland and Antarctic ice sheets and shelves and contributions to sea-level rise: 1992-2002. J. Glaciol., 51(175), 509-527 